\title{
Geometrical Parametric Optimisation of A356 Alloy Composite in a Two- Stage Casting Process for Automobile Wheel Covers using Response Surface Methodology
}

\author{
Stephen Chidera Nwafor, Sunday Ayoola Oke*, Chris Abiodun Ayanladun \\ Department of Mechanical Engineering, University of Lagos, Lagos, Nigeria
}

\begin{abstract}
In recent years, novel products from out-of-use A356 alloy engine components are increasingly produced for the automobile industries. Despite being a promising method, the sand casting of these products reveals an inadequately understood cast geometry phenomenon for the process. At present, there is no technical solution (composite computational model) to the optimisation of cast geometries for A356 alloy reconfigured into composites through organic matter reinforcements. In this paper, models and analyses of the sand casting process with product geometries in a two-phase method are discussed. It utilises the response surface methodology with data on inputs and outputs to create the regression. Volume and density of the first casting process and the weight loss were evaluated for the various groupings of casting process variables, including length, weight, height, the width of product for the first casting, weight, length, breadth of the product for the second casting, and the total weight of organic materials. The input and output associations were established in two models of regression analysis representing the central composite design, CCD. The influences of the cast geometrical variables on the evaluated responses were analysed. Furthermore, the predictive accuracy of the two regression models was evaluated. Results revealed that the applied CCD and the regression models display statistical adequacy and are competent to predict accurately.
\end{abstract}

Keywords: Sand casting,Response surface methodology, Optimisation, A356 alloy composites

\section{Introduction}

\subsection{General}

Gaining insight into the optimisation of process parameters to enhance castability and reduce casting defects of A356 alloy reinforced with combined abori wood (AW), pineapple sucker (PS), and Delonix regia (D) is an important engineering practice to meet up with the service demands for wheel covers, brake drum and connecting rods and this is the focus of the current study [1-5]. The material studied here is the A356 alloy/AW/PS/D composite that is produced through the sand casting process. Given the application (wheel cover for a four-wheel Toyota car), the anticipated material properties are obtained from an appropriate selection of reinforcement in particulate form [6-9]. The literature on composites is deficient in the details of the sand casting of A356 alloy/AW/PS/D and consequently, this research is the foremost report in selecting the constituents of reinforcements and the aluminium matrix. Abandoned A356 alloy (in form of disposal worn-out engine blocks) were melted in a local furnace at a foundry in Fola Agoro area of Lagos, Nigeria and the melts are mixed with particulates of AW, PS

\footnotetext{
* Corresponding author. Tel.: +234-8058179170
}

E-mail address: sa_oke@yahoo.com

Manuscript History:

Received 24 March, 2020, Revised 24 April, 2020, Accepted 24 April, 2020, Published 30 April, 2020

e-ISSN: 2289-7771 
and D. These particulates include waste from sawn wood planks (i.e. abori wood particles) obtained from the carpentry section of the Engineering Faculty, University of Lagos. The pineapple sucker (PS) was collected from the main gate of the University of Lagos, and ground milled in a local market in Bariga community after being sun-dried and found to contain no moisture. The Delonix regia reinforcement was obtained from a tree on the campus of the University of Lagos. The processing of the Delonix regia reinforcement into particulate form also follows a similar procedure of the PS.

\subsection{Research problem and novelty}

Wheel covers for automobiles protect the wheels from direct contacts with corrosion agents and offer good aesthetics for vehicles. To offer superior wheel covers with attractive mechanical, wear and metallurgical characteristics and at a reduced cost, this project initiative, Project 1.0, was installed. At present, wheel covers are sourced from overseas into Nigeria. The demand for wheel covers exceeds the supply. While imported wheel covers are light, they are expensive. Besides, the improperly disposed engine blocks that constitute the matrix for wheel covers provide an opportunity of saving governments' clearing and health costs when used for wheel cover production. Furthermore, there is an increasing environmental threat that engine blocks pose to the environment. Engine blocks are not biodegradable and the use of organic biodegradable materials as reinforcements in A356 alloy composite has not been exploited [5, 10-12]. So, to what extent has the disposed engine blocks (i.e. A356 alloy) and wastes (i.e. abori wood, pineapple sucker and Delonix regia tree droppings) been successful in producing superior, low-cost wheel covers that the effort of government in "waste conversion to wealth" is intended to produce? Can a new composite be developed that will reduce the environmental nuisance of waste disposal in developing countries?

Arising from the foregoing, Project 1.0 brings about a novelty that should be exploited to the benefit of the research community. The key objective of this paper is to optimise the sand casting process and product geometric parameters of the A356 alloy matrix reinforced with varying percentages of combined particulate abori wood, pineapple suckers and Delonix regia using the response surface methodology (RSM). Despite that many scholars have worked on the modification of A356 alloy, very scanty reports could be found with organic-based modifications. Enhancement of mechanical properties of A356 alloy with extra alloying elements is the main avenue of promoting its extended use in many applications such as the wheel cover of automobile vehicles. The dimensions of the wheel covers in tyres of the Toyota brand of car is taken into consideration and with the addition of organic matters of AW, PS, and D, improved environmental friendly manufacturing of wheel cover was noticed. However, despite the mixing difficulties of obtaining homogeneous compounds, the final and intermediate casts were found to be within permissible production limits. This data may serve as expedient information to cast and design wheel covers of tyres in automobiles.

Several scholars have added different alloying elements to the A356 alloy, such as La/Ce (rare elements) [13], trace element La [14]. Though their works are similar in that they are modifications of the A356 alloy, however, in the present study, the modifications are done through the addition of organic reinforcements and their performance is investigated. The abori wood, pineapple sucker and Delonix regia wastes are ground into fine particles and blended at the second phase of casting. In the present

study, the interactive effects and the weight percentages of the combined AW, PS and D are studied extensively. The influences of these additions with the products geometric parameters of length, weight, height and density are as well investigated. This outcome of the insight is used to decide in what proportions the reinforcements are to be added to the A356 alloy in the design and casting stages of the A356 alloy composite.

From the literature review, it was noted that research that generally tackles optimisation of casting process parameters of the A356 alloy modification is limited to some additives of rare elements (La, $\mathrm{Ce})$ and cow horn. Nonetheless, there are very restricted studies on the optimisation of organic-based A356 alloy composites. The demand for environmentally friendly composites both during usage and at 
their end-of-life disposal phase is high for wheel covers of automobile cars. Besides, no clear results on wood-based A356 alloy have been reported. Also no records of any applications of A566 alloy composite casting that has involved pineapple sucker and Delonix regia wastes and also none that combines them as reinforcements to A356 alloy matrix. Consequently, this research makes an effort to bridge this knowledge gap identified by ascertaining the interrelatedness of the wide-ranging parameters and idea in the course of A356 alloy/AW/PS/D composite. The cast A356 alloy coupled with the organic reinforcements using the sand casting method is on the increase being exposed to the influence of the interactions of the matrix elements and the actions of the particulates of the reinforcement in its interlocking activities coupled with the heat produced during casting. Consequently, gaining insight into the mechanical property concerns of casting and the process parametric interfaces are a must requirement to tackle the confrontations during the casting of A356 alloy/AW/PS/D composite. The objectives of the research are then stated as follows:

- Gain insight into the composition of A356 alloy/AW/PS/D composite in its various combinations of weight percentages

- Optimise the casting process parameters to enhance castability and reduce the environmental effects of disposed A356 alloy

\section{Literature review}

An examination of research articles concerning this research domain is offered in the present section. This analysis also offers the up-to-date developments in the field of A356 alloy composite. The review of literature spans across a comprehensive analysis on RSM on composites and the various applications and theories regarding A356 alloy composites.

\subsection{Response surface methodology}

The RSM is a successful optimisation technique, widely applied in diverse fields, including friction welding, dielectric discharge systems, electric discharge systems, electric discharge machining, wear technology, machining and squeeze casting. The foundation of the technique is laid on the joint interactions of statistical techniques (notably non-linear regression models) and experimental designs. The use of RSM involves developing empirical models and determining the parameters models are statistically significant or not [15]. The RSM performs well to describe real-world circumstances with the empirical model, with logics and effectiveness and can be useful to model complicated manufacturing problems such as the cast geometry problem involving parametric determination and optimisation in the course of sand casting A356 alloy which is reinforced with organic materials. Consequently, there is a clearly defined research gap in the casting of A356 alloy composite that would be solved by using the RSM. As a result, in this work, a mathematical model of the RSM is developed by inheriting the advantages of the method in an optimisation process. The RSM is very commonly used to optimise process parameters in the diverse manufacturing areas, including machining, wear analysis, casting process among others.

In the main area of this study which concerns A356 alloy composite, the track record of research due to Palanikumar et al. [16] could be noted. The authors tried to understand the machining behaviour of A356 alloy composites reinforced with silicon carbide particulates by using the lathe machine and the poly-crystalline carbide inserts at different cutting circumstances. Balasubramanian et al. [17] used RSM to optimise the CNC turning parameters for the LM6/SiCp composite. The RSM was asserted as a successful method to predict the expected accomplishment of the process efficiently and effectively. Bawono et al. [18] formulated a machining strategy by CNC milling of an insole shoe for diabetic patients using response surface approach. By reviewing these papers on machining that have applied response surface approach to optimise their parameters, some useful insights were gained on the utility

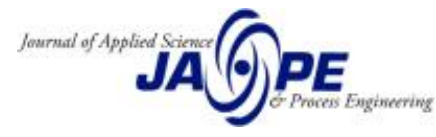


of the approach. However, the useful technique of RSM has not been applied to the A356 alloy composites reinforced with organic materials.

Now, beyond machining, RSM has also been applied in several diverse areas, including the following. Radhika and Raghu [19] applied RSM to the wear of functionally graded composites of $\mathrm{Al} / \mathrm{TiB}_{2}$. Patel et al. [20] applied RSM to the squeeze casting process. They concluded that the central composite design and Box-Behnken design as well as the regression models obtained revealed statistically-appropriate behaviour and displayed the capability to make precise predictions. Mohal and Kumar [21] analysed the parameters machining process when processing $\mathrm{Al}-10 \% \mathrm{SiC}_{\mathrm{p}}$ composite through the electrical discharge machining system. The application of RSM was made in the work. Adalarasan et al. [22] applied the response surface technique to composite production involving $\mathrm{Al} / \mathrm{SiC}_{\mathrm{Al}} \mathrm{O}_{2} \mathrm{O}_{3}$ composite using friction welding. It was concluded that optimal situations exist and was validated by experiments and through microscope images. The RSM was applied to optimise the generation of ozone. Alvarez et al. [23] reported on how to apply genetic algorithms within the framework of response surface technique to solve optimisation problems.

\subsection{The A356 alloy composite literature}

Mishra et al. [24] demonstrated the contribution of ratcheting stress and damage on the tensile character of A356 alloy at ambient temperature with changing average stress and amplitude stress. Zhang et al. [25] developed a novel procedure for near rapid solidification and thermomechanical treatment (TMT) processing. It was found that A356 poses higher yield stress at reduced solid fraction Fs $<0.95$ rises in grain size. SDAS brings about reduced semi-solid ductility in A356 and B206. The contribution of Ti powder to microstructure mostly in both morphology and L-crystal with mechanical qualities was examined by Liu et al. [26]. The $1.5 \% \mathrm{wt}$ and 3.0\%wt of Ti powder molten A356 at the raised temperature of $780^{\circ} \mathrm{C}$ was considered. Lin et al. [27] studied the interfacial heat transfer coefficient of metal moulding casting and caring of A356 gravity casting using a non-linear estimation method for inverse heat conduction problem. Nwobi-Okoye et al. [3] applied artificial neural network and adaptive neuro-fuzzy inference system to model the age hardening of A356 cow-horn particulate composite. Pramod et al. [28] worked on the influence of Sc and T6 ageing enhancement on the mechanical character of A356 alloy. Jadha et al. [10] used $\mathrm{B}_{4} \mathrm{C}$ and graphite powder to strength A356 aluminium alloy in two-phase melt stirring process preferred to mono mixing method for agglomeration of the powder and industrial enhanced characteristics of the A356-L graphite formed. Das et al. [29] presented a computational fluid dynamic model to research among rheo-pressure die casting (RPDC) system using vehicle steering knuckle cavity while the slurring is a product of A356 alloy. Experiments were carried out to establish the CFD model applied. Nie et al. [30] studied the wrought 6061-T6 and cast A356-T6 aluminium alloys MiG welded joint microstructure and mechanical regions. The influence of including $\mathrm{Eu}$ and thermal enhancement of T6 on A356 alloy's microstructure and mechanical qualities were researched by Mao et al. [1]. Ma et al. [2] studied the influence brought by stress concentration to dislocation motion. They applied a scanning electron microscope and an optical microscope to research on Si particles and fracture development trend in A356 alloy between $20^{\circ} \mathrm{C}$ and $-60^{\circ} \mathrm{C}$ via the test of tensile samples and notch tensile samples.

\subsection{Summary of literature review}

By following the outcome of the literature review, the subsequent interpretations are made from the review

1. From a compilation of methods, the RSM is found to be effective in offering quantitative nature of data with outcomes that could easily be interpreted

e-ISSN: 2289-7771

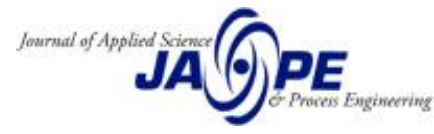


2. Many studies in the literature have focused on the influence of one alloying element on the other on the microstructural behaviour of the A356 alloy composite. Consequently, investigations of cast geometries are of huge benefit to melt shops and the research community in general.

3. In many studies on A356 alloy composites, metallic reinforcements are more widely used than organic matters. However, in industries, there is an overwhelming pressure on composite producers to use environmentally-friendly reinforcements such as organic compounds. Thus, research is needed on A356 alloy composite development by using organic-based reinforcements to enhance the environmental compliance of composite development. Organic reinforcements will reduce the weights of the composites while maintaining ecological requirements.

4. For a complicated and irregular casting process involving two phases of production, an innovative and elevated method of response surface approach will offer superior outcome to carry out the optimisation of geometries of the cast parameters for the sand casting process

5. By associating the volume of cast 1 , the density of cast 1 and the weight loss of the casting process with each of the lengths (for casts 1 and 2), breadth, width and density and volume of cast 2, it is possible to optimise the cast geometries of the two phases of a canoe-shaped and cuboid-shaped geometries of A356 alloy casts with the addition of organic materials as reinforcements to the A356 alloy. With the success of optimising the cast geometries, the product design productivity will be elevated and the quality of casting will improve. Thus, the RSM of optimisation was concluded as an appropriate method to apply to optimise the case geometries of the mentioned product. The data that verifies this claim is from a melt shop operating in Lagos.

6. Over the years, the cast technology literature has made concerted efforts to enhance cast decisions and cast productivity by substituting innovative technique application for intuitive decisions of the rule of the thumb. Since this gap was noticed, RSM appears to be the best option for the conventional mindset in cast technology.

\section{Methodology}

In this paper, a literature review was conducted on the most important aspects of the A356 alloy composites and the RSM. It was concluded that a broad investigation on the geometrical characteristics, which involves the two-phase casting of A356 alloy matrix and organic matters should be conducted. Besides, efforts were directed to optimise the cast geometries of the A356 alloy composite in the sand casting process. Although the literature review suggests a long history of geometrical optimisation of solid objects, only recently have researchers commenced to study the casting process. As a consequence, the only available optimisation tool in this research domain is the Taguchi method, which has been applied recently by a group of researchers [31]. The need for more testing has, therefore, prompted the current authors to consider the advantages and disadvantages of the RSM as a candidate for investigation. Researchers have criticized the RSM as a "black box" which challenges efforts to analyse the degree of approximation errors. Furthermore, the RSM gives results for local analysis such that the established response surface becomes unacceptable for territories outside the range of factors. But the RSM is widely used in engineering research including welding and machining. It is also considered as a useful tool for both single and multiple responses. Since the geometrical optimisation problem considered is a multi-response concern, it is thought to be adequate for the current investigation. Furthermore, since the sand casting data may be well fitted to a second-order polynomial, the RSM may be appropriate. Consequently, after considering the advantages with the disadvantages of the available optimisation tools for cast geometrical optimisation, the RSM was chosen to define the utmost performance of the cast geometries for the A356 alloy composite. In applying the methodology of the response surface, the data on experiments related to A356 alloy reinforced with organic matter is employed to examine and appraise the model to attain the diverse features of the model. The key examination of the A356 alloy composite data is channelled through the use of analysis of variance that offers details on the numerical nature of the problem to obtain the $p$-value. The RSM model would be judged as significant in instances where the $p$-values are lower than 0.05 and insignificant otherwise.

e-ISSN: 2289-7771 
The value of $p<0.05$ was set as a reasonable cut-off to establish significance. It indicates a chance in twenty of being wrong. However, since for the experiments considered it is suitable for the reliability of the casts, higher confidence levels may not be necessary. For the current study, the various models are built up to obtain responses from the perspectives for the real factors, presented subsequently:

In the area of composite casting where attention is directed to cast geometries, the output variable of necessity (response) and a set of independent variables have associations. As established by Pai et al. [32], the relationship could involve many variables $\left\{\psi_{1}, \psi_{2}, \ldots, \psi_{\mathrm{n}}\right\}$. According to the author and other reported investigations, the kind of correlation between response and independent variables values in particular schemes could be established. From the perspective of variables stated earlier, Pai et al. [32] express the association between the dependent and independent variables as (Equation 1):

$$
J=f\left(\psi_{1}, \psi_{2}, \ldots, \psi_{\mathrm{n}}\right)+\grave{\varepsilon}
$$

where $\grave{\varepsilon}$ is error observed in the response $J$. If the likely response is assigned as follows [32] (Equation 2):

$$
E(J)=f\left(\psi_{1}, \psi_{2}, \ldots, \psi_{\mathrm{n}}\right)=\hat{J}
$$

then the response surface denoted by Pai et al. [32] (Equation 3):

$$
\hat{J}=f\left(\psi_{1}, \psi_{2}, \ldots, \psi_{\mathrm{n}}\right)
$$

In Pai et al. [32], it was stated that the type of correlation between the response and the independent variable is unknown, hence, the initial action in RSM is to attain an appropriate estimation for the proper efficient correlation between the response and set of independent variables used. A second-order model is generally applied in the RSM and it is usually employed when the response function is unknown or nonlinear [32] (Equation 4):

$$
\hat{J}=\phi_{0}+\sum_{i=1}^{Q} \phi_{i} \Psi_{i}+\sum_{i=1}^{Q} \phi_{i i} \Psi_{i}^{2}+\sum_{i} \sum_{j} \phi_{i j} \Psi_{i} \Psi_{j}+\varepsilon
$$

The $\phi$ coefficients, employed in the model in Equation (4) could be appraised through the least square approach [32].

Furthermore, in this work, the cause and effect relationship between inputs or factors (length of cast 1 (LC1), weight of cast 1 (WC1), height of cast 1 ( $\mathrm{HC} 1)$, width of cast 1 (WiC1), weight of cast 2 (WC2), length of cast 2 (LC2), breadth of cast 2 (BC2), total weight of organic materials (TWOM)) and outputs or response (volume of cast 1, density of cast 1 and weight loss) was investigated [33]. Equation (5) shows the second-order relationship between the experimental factors and the responses [33].

$$
\begin{aligned}
J=\phi_{0}+ & \phi_{1} L C 1+\phi_{2} W C 1+\phi_{3} H C 1+\phi_{4} W i C 1+\phi_{5} W C 2+\phi_{6} L C 2+\phi_{7} B C 2+\phi_{8} T W O M \\
& +\phi_{11} L C 1^{2}+\phi_{22} W C 1^{2}+\phi_{33} H C 1^{2}+\phi_{44} W i C 1^{2}+\phi_{55} W C 2^{2}+\phi_{66} L C 2^{2} \\
& +\phi_{77} B C 2^{2}+\phi_{88} T W O M^{2}+\phi_{12} L C 1 * W C 1+\phi_{13} L C 1^{*} H C 1+\phi_{14} L C 1 * W i C 1 \\
& +\phi_{15} L C 1^{*} W C 2+\phi_{16} L C 1 * L C 2+\phi_{17} L C 1 * B C 2+\phi_{18} L C 1 * T W O M \\
& +\phi_{23} W C 1 * H C 1+\phi_{24} W C 1 * W i C 1+\phi_{25} W C 1 * W C 2+\phi_{26} W C 1 * L C 2 \\
& +\phi_{27} W C 1 * B C 1+\phi_{28} W C 1 * T W O M+\phi_{34} H C 1 * W i C 1+\phi_{35} H C 1^{*} W C 2 \\
& +\phi_{36} H C 1 * L C 2+\phi_{37} H C 1 * B C 2+\phi_{38} H C 1 * T W O M+\phi_{45} W i C 1 * W C 2
\end{aligned}
$$




$$
\begin{aligned}
& +\phi_{46} W i C 1 * L C 2+\phi_{47} W i C 1 * B C 2+\phi_{48} W i C 1 * T W O M+\phi_{56} W C 2 * L C 2 \\
& +\phi_{57} W C 2 * B C 2+\phi_{58} W C 2 * T W O M+\phi_{67} L C 2 * B C 2+\phi_{68} L C 2 * T W O M \\
& +\phi_{78} B C 2 * T W O M
\end{aligned}
$$

Equations (1) to (5) in this study are very useful for predictive purposes of the geometrical parameters for the A356 alloy composite

The central composite design is adopted in this experiment. Eight factors were used in the central composite design. This experiment has eight factors at three levels. The factors (length of cast 1(LC1), weight of cast 1 (WC1), height of cast $1(\mathrm{HC} 1)$, width of cast 1 (WiC1), weight of cast 2 (WC2), length of cast 2 (LC2), breadth of cast 2 (BC2), total weight of organic materials (TWOM)) and their levels are shown in Table 1.

Table 1. Factors and levels of A356 alloys for the problem

\begin{tabular}{ccccl}
\hline S/No. & $\begin{array}{l}\text { Factor } \\
\text { (parameter) }\end{array}$ & $\begin{array}{c}\text { Level } \\
1\end{array}$ & $\begin{array}{c}\text { Level } \\
2\end{array}$ & $\begin{array}{c}\text { Level } \\
3\end{array}$ \\
\hline 1 & LC1 & 0.286 & 0.282 & 0.286 \\
2 & WC1 & 1.898 & 1.826 & 1.998 \\
3 & HC1 & 0.038 & 0.036 & 0.039 \\
4 & WiC1 & 0.101 & 0.097 & 0.1 \\
5 & WC2 & 1.77 & 1.68 & 1.83 \\
6 & LC2 & 0.264 & 0.264 & 0.264 \\
7 & BC2 & 0.24 & 0.241 & 0.24 \\
8 & TWOM & 0.2847 & 0.23 & 0.1996 \\
\hline
\end{tabular}

\section{Results and discussion}

The experimental design matrix, the factors and responses are shown for A356 alloy in Table 2. However, the analysis was made using Minitab-16 software. The analysis of variance, ANOVA, has been demonstrated in the literature to show how stable the RSM is through a validation process. The $p$ values show if the tests of hypothesis are significant or not. From the study, the result reveals the significance of the model, exhibiting $p$-values not up to 0.001 while the comparison is made against a restricted value of 0.05 . Details of the statistics concerning regression, the $R^{2}$, which is often referred to as the goodness of fit, as well as the adjusted $R^{2}$, which is designated as the predictive goodness, are obtained regarding all the responses involved in the analysis. The evaluation parameter, $R^{2}$, displays a value that shows the wide range of variability of the response when all the substantial parameter have been considered. Moreover, the evaluation parameters, adjusted $R^{2}$ displays a value that takes care of the amount of the predictors obtainable in the model. It is interesting to know that the evaluation parameters $R^{2}$ and adjusted $R^{2}$ displays values, which reveal that the constructed model has a very good fit to the data used from the A356 alloy opposite development process. The mean, standard deviation, $R^{2}$ and adjusted $R^{2}$ are subsequently shown. Validation of the RSM model for A356 alloy composite was made based on the best system parameters obtained. In particular, an average result was obtained.

\subsection{Central composite design}

In this work, the different cases to optimise the cast configurations of A356 alloy reinforced with organic materials (AW, PS and D) are discussed. Eight factors are considered, classified as inputs and outputs. The input factors are $\mathrm{LC} 1, \mathrm{WC} 1, \mathrm{HC} 1, \mathrm{WiC} 1, \mathrm{WCZ}, \mathrm{LCZ}, \mathrm{BC} 2$ and TWOM while the output factors are volume of cast 1, density of cast 1 and weight loss (Table 1). To enhance the geometries in the various cases considered, the output variables of importance (responses) and the group of independent variables are studied. The design of experiments was employed to gain insight into the 
cause and effect association between the inputs and the responses [33]. Equation (5) reveals the secondorder association between the experimental factors and the responses. The regression analysis was used as an indicator of performance to determine what factors are statistically significant to the responses and otherwise. So, three case studies were considered for analysis. These case studies were drawn from a publication of Nwafor et al. [31] and analysis drawn from Tables 2, 3 and 4 of the paper. These tables from Nwafor et al. [31] reveal the basic data that serves as input in the development and analysis of the RSM model proposed in this work. They contain the original data that transformed into the analysed parameters and their associated levels. The data used for RSM include measures on volume, length, density, height and width of the canoe-shaped specimens. Others are the width, length, and breadth for the cuboid-shaped specimens. However, during the transformation of the cast specimens from the canoeshaped outlook to cuboid-shaped outlook, some weight losses are expected in the casting process, which is accounted for in the data. Furthermore, the total weight of the organic material is also of interest and the data is revealed in Nwafor et al. [31]. Furthermore, concerning Table 3 of Nwafor et al. [31], nine samples were used in the experimentation apart from the control sample. Here, to obtain the input data, the mean of three consecutive values (the first method) was used. This entails taking the average of the first three data points in each of the columns " $\mathrm{A}$ " to " $\mathrm{K}$ ", and allowing this to represent the first level for "A", which is the volume of cast 1. For instance, this value gives 0.000446 and is recorded as the first level in Table 2 of Nwafor et al. [31]. Similar computations are made for other entries under "B" to " $\mathrm{K}$ ", representing the entries put on the first column under level 1 as $0.286, \ldots, 0.2847$. To obtain the values for level 2 , the next three items are averaged and the procedure for determining values earlier stated followed. Furthermore, all the levels for the parameters are determined in this manner. The second method entails the same procedure but with an amendment. When the three values are chosen, the minimum is recorded. For the third method, as three values are considered, the maximum value is used. The three methods are options in which any of them could be used for further analysis and decisions. However, the results of these methods could facilitate comparison. It could assist to verify the correctness of the approaches and data. The work referred to analysed the geometric optimisation of the casting process involving A356 alloy composite. The argument offered in the current study is that although Taguchi optimisation may reveal the important parametric insights into the cast geometry composite problem, there is an extensive scope to study the concerns associated with the optimisation of cast geometries for A356 alloy composite. With the application of RSM proposed in the present work, the greater insight into solving the optimisation problem could be obtained while the problem is tackled and analysed. So, the three case studies examined in this work are as follows. The problem analyses the original data set and used the mean value of these data sets. The mean value of the first three consecutive values is employed (Table 2 of Nwafor et al. [31]). For each case, three responses were considered (Volume of cast 1, Density of cast 1 and Weight loss).

The regression coefficients were determined (Table 3 ) for the volume of cast 1 , the density of cast 1 and weight loss, respectively. For the situation considered and three responses, the following observations were made. For the first response, volume of cast 1 , two factors, $\mathrm{WC} 1 * \mathrm{WiC} 1$ and TWOM*LC2 were statistically significant to the response. The reason is that their $p$-values, which are 0.009 and 0.029 , respectively are less than 0.05 . Notice that the $p$ values show if the tests of hypothesis are significant or not. The model shows a $54.63 \%$ in light output, which is the $\mathrm{R}-$ sq value. The model is also overfitted because the $R-\mathrm{sq}$ (pred) is $0.00 \%$. For the second response, these factors are $\mathrm{WC} 1 * \mathrm{WiC} 1$ and $\mathrm{HC} 1 * \mathrm{BC} 2$ with the values of 0.035 and 0.036 , respectively, as displayed in Table 3 . The $\mathrm{R}$-sq value shows that the model has a $54.94 \%$ in light output and it is overfitted due to the $0.00 \%$ value of $\mathrm{R}$-sq (pred). This information is revealed in Table 3. Concerning the weight loss, the regression analysis for the response is displayed in Table 3. The model has $53.29 \%$ behaviour in light output and it is also overfitting. In this case, three factors, $\mathrm{LC} 1 * \mathrm{LC} 1, \mathrm{WC} 1 * \mathrm{WC} 2$ and $\mathrm{TWOM} * \mathrm{WiC} 2$ are statistically significant with $p$-values of $0.038,0.036$ and 0.021 , respectively. The linear, square and interactions in Table 4 are also insignificant.

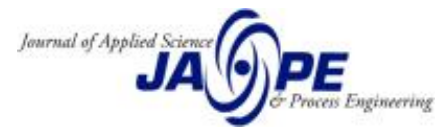


Table 2. Experimental design matrix with the factors and responses of A356 alloy model 1

\begin{tabular}{|c|c|c|c|c|c|c|c|c|c|c|c|c|c|c|c|c|c|c|c|}
\hline \multirow{2}{*}{ No } & \multicolumn{8}{|c|}{ Coded values } & \multicolumn{8}{|c|}{ Actual values } & \multicolumn{3}{|c|}{ Response } \\
\hline & $\mathrm{A}$ & B & $\mathrm{C}$ & $\mathrm{D}$ & $\mathrm{E}$ & $F$ & G & $\mathrm{H}$ & LC1 & WC1 & $\mathrm{HC} 1$ & WiC1 & WC2 & LC2 & $\mathrm{BC} 2$ & TWOM & VC1 & DC1 & WL \\
\hline 1 & 1 & -1 & -1 & 1 & -1 & -1 & 1 & -1 & 0.286 & 1.826 & 0.036 & 0.101 & 1.68 & 0.26 & 0.241 & 0.200 & 0.000446 & 4271.1 & 0.13 \\
\hline 2 & 0 & 0 & 0 & 0 & 0 & 0 & 0 & 0 & 0.284 & 1.912 & 0.0375 & 0.099 & 1.755 & 0.262 & 0.2405 & 0.242 & 0.000381 & 5379.9 & 0.146 \\
\hline 3 & -1 & 1 & 1 & -1 & -1 & -1 & 1 & -1 & 0.282 & 1.998 & 0.039 & 0.097 & 1.68 & 0.26 & 0.241 & 0.200 & 0.000471 & 4545.1 & 0.172 \\
\hline 4 & 0 & 0 & 0 & 0 & 0 & 0 & 0 & 0 & 0.284 & 1.912 & 0.0375 & 0.099 & 1.755 & 0.262 & 0.2405 & 0.242 & 0.000446 & 4271.1 & 0.13 \\
\hline 5 & 1 & 1 & -1 & 1 & 1 & -1 & -1 & -1 & 0.286 & 1.998 & 0.036 & 0.101 & 1.83 & 0.26 & 0.24 & 0.200 & 0.000381 & 5379.9 & 0.146 \\
\hline 6 & 1 & 1 & 1 & -1 & -1 & -1 & -1 & 1 & 0.286 & 1.998 & 0.039 & 0.097 & 1.68 & 0.26 & 0.24 & 0.285 & 0.000471 & 4545.1 & 0.172 \\
\hline 7 & 1 & -1 & -1 & 1 & 1 & -1 & 1 & 1 & 0.286 & 1.826 & 0.036 & 0.101 & 1.83 & 0.26 & 0.241 & 0.285 & 0.000446 & 4271.1 & 0.13 \\
\hline 8 & 1 & 1 & 1 & 1 & 1 & -1 & 1 & -1 & 0.286 & 1.998 & 0.039 & 0.101 & 1.83 & 0.26 & 0.241 & 0.200 & 0.000381 & 5379.9 & 0.146 \\
\hline 9 & -1 & -1 & -1 & -1 & 1 & 1 & 1 & 1 & 0.282 & 1.826 & 0.036 & 0.097 & 1.83 & 0.264 & 0.241 & 0.285 & 0.000471 & 4545.1 & 0.172 \\
\hline 10 & 1 & 1 & -1 & 1 & 1 & 1 & -1 & 1 & 0.286 & 1.998 & 0.036 & 0.101 & 1.83 & 0.264 & 0.24 & 0.285 & 0.000446 & 4271.1 & 0.13 \\
\hline 11 & 1 & -1 & -1 & -1 & 1 & -1 & -1 & 1 & 0.286 & 1.826 & 0.036 & 0.097 & 1.83 & 0.26 & 0.24 & 0.285 & 0.000381 & 5379.9 & 0.146 \\
\hline 12 & 1 & -1 & 1 & -1 & -1 & 1 & 1 & 1 & 0.286 & 1.826 & 0.039 & 0.097 & 1.68 & 0.264 & 0.241 & 0.285 & 0.000471 & 4545.1 & 0.172 \\
\hline 13 & 1 & 1 & 1 & 1 & -1 & 1 & 1 & -1 & 0.286 & 1.998 & 0.039 & 0.101 & 1.68 & 0.264 & 0.241 & 0.200 & 0.000446 & 4271.1 & 0.13 \\
\hline 14 & -1 & 1 & -1 & -1 & 1 & -1 & -1 & 1 & 0.282 & 1.998 & 0.036 & 0.097 & 1.83 & 0.26 & 0.24 & 0.285 & 0.000381 & 5379.9 & 0.146 \\
\hline 15 & 1 & 1 & -1 & -1 & -1 & 1 & 1 & -1 & 0.286 & 1.998 & 0.036 & 0.097 & 1.68 & 0.264 & 0.241 & 0.200 & 0.000471 & 4545.1 & 0.172 \\
\hline 16 & -1 & -1 & 1 & -1 & -1 & 1 & -1 & -1 & 0.282 & 1.826 & 0.039 & 0.097 & 1.68 & 0.264 & 0.24 & 0.200 & 0.000446 & 4271.1 & 0.13 \\
\hline 17 & 1 & -1 & -1 & -1 & 1 & 1 & -1 & -1 & 0.286 & 1.826 & 0.036 & 0.097 & 1.83 & 0.264 & 0.24 & 0.200 & 0.000381 & 5379.9 & 0.146 \\
\hline 18 & -1 & -1 & 1 & -1 & 1 & -1 & -1 & -1 & 0.282 & 1.826 & 0.039 & 0.097 & 1.83 & 0.26 & 0.24 & 0.200 & 0.000471 & 4545.1 & 0.172 \\
\hline 19 & 1 & -1 & 1 & 1 & 1 & 1 & -1 & -1 & 0.286 & 1.826 & 0.039 & 0.101 & 1.83 & 0.264 & 0.24 & 0.200 & 0.000446 & 4271.1 & 0.13 \\
\hline 20 & 1 & -1 & 1 & -1 & 1 & 1 & 1 & -1 & 0.286 & 1.826 & 0.039 & 0.097 & 1.83 & 0.264 & 0.241 & 0.200 & 0.000381 & 5379.9 & 0.146 \\
\hline 21 & -1 & 1 & -1 & 1 & -1 & 1 & 1 & 1 & 0.282 & 1.998 & 0.036 & 0.101 & 1.68 & 0.264 & 0.241 & 0.285 & 0.000471 & 4545.1 & 0.172 \\
\hline 22 & -1 & 1 & -1 & 1 & 1 & -1 & 1 & 1 & 0.282 & 1.998 & 0.036 & 0.101 & 1.83 & 0.26 & 0.241 & 0.285 & 0.000446 & 4271.1 & 0.13 \\
\hline 23 & 1 & 1 & 1 & 1 & 1 & 1 & 1 & 1 & 0.286 & 1.998 & 0.039 & 0.101 & 1.83 & 0.264 & 0.241 & 0.285 & 0.000381 & 5379.9 & 0.146 \\
\hline 24 & 1 & -1 & -1 & 1 & 1 & 1 & 1 & -1 & 0.286 & 1.826 & 0.036 & 0.101 & 1.83 & 0.264 & 0.241 & 0.200 & 0.000471 & 4545.1 & 0.172 \\
\hline 25 & 1 & 1 & -1 & -1 & 1 & -1 & 1 & -1 & 0.286 & 1.998 & 0.036 & 0.097 & 1.83 & 0.26 & 0.241 & 0.200 & 0.000446 & 4271.1 & 0.13 \\
\hline 26 & 0 & 0 & 0 & 0 & 0 & 0 & 0 & 0 & 0.284 & 1.912 & 0.0375 & 0.099 & 1.755 & 0.262 & 0.2405 & 0.242 & 0.000381 & 5379.9 & 0.146 \\
\hline 27 & 0 & 0 & 0 & 0 & 0 & 0 & 0 & 0 & 0.284 & 1.912 & 0.0375 & 0.099 & 1.755 & 0.262 & 0.2405 & 0.242 & 0.000471 & 4545.1 & 0.172 \\
\hline 28 & -1 & -1 & -1 & 1 & -1 & -1 & -1 & 1 & 0.282 & 1.826 & 0.036 & 0.101 & 1.68 & 0.26 & 0.24 & 0.285 & 0.000446 & 4271.1 & 0.13 \\
\hline 29 & 1 & 1 & 1 & 1 & -1 & -1 & 1 & 1 & 0.286 & 1.998 & 0.039 & 0.101 & 1.68 & 0.26 & 0.241 & 0.285 & 0.000381 & 5379.9 & 0.146 \\
\hline 30 & -1 & -1 & 1 & 1 & -1 & 1 & 1 & -1 & 0.282 & 1.826 & 0.039 & 0.101 & 1.68 & 0.264 & 0.241 & 0.200 & 0.000471 & 4545.1 & 0.172 \\
\hline 31 & 0 & 0 & 0 & 0 & 0 & 0 & 0 & 0 & 0.284 & 1.912 & 0.0375 & 0.099 & 1.755 & 0.262 & 0.2405 & 0.242 & 0.000446 & 4271.1 & 0.13 \\
\hline 32 & 1 & -1 & 1 & -1 & 1 & -1 & 1 & 1 & 0.286 & 1.826 & 0.039 & 0.097 & 1.83 & 0.26 & 0.241 & 0.2847 & 0.000381 & 5379.9 & 0.146 \\
\hline 33 & -1 & 1 & -1 & -1 & -1 & -1 & -1 & -1 & 0.282 & 1.998 & 0.036 & 0.097 & 1.68 & 0.26 & 0.24 & 0.200 & 0.000471 & 4545.1 & 0.172 \\
\hline 34 & 0 & 0 & 0 & 0 & 0 & 0 & 0 & 0 & 0.284 & 1.912 & 0.0375 & 0.099 & 1.755 & 0.262 & 0.2405 & 0.242 & 0.000446 & 4271.1 & 0.13 \\
\hline 35 & -1 & 1 & 1 & 1 & -1 & -1 & -1 & -1 & 0.282 & 1.998 & 0.039 & 0.101 & 1.68 & 0.26 & 0.24 & 0.200 & 0.000381 & 5379.9 & 0.146 \\
\hline 36 & -1 & 1 & 1 & -1 & 1 & 1 & 1 & -1 & 0.282 & 1.998 & 0.039 & 0.097 & 1.83 & 0.264 & 0.241 & 0.200 & 0.000471 & 4545.1 & 0.172 \\
\hline 37 & -1 & -1 & -1 & -1 & -1 & 1 & 1 & -1 & 0.282 & 1.826 & 0.036 & 0.097 & 1.68 & 0.264 & 0.241 & 0.200 & 0.000446 & 4271.1 & 0.13 \\
\hline 38 & 1 & 1 & -1 & -1 & 1 & 1 & 1 & 1 & 0.286 & 1.998 & 0.036 & 0.097 & 1.83 & 0.264 & 0.241 & 0.285 & 0.000381 & 5379.9 & 0.146 \\
\hline 39 & 1 & -1 & 1 & 1 & -1 & -1 & -1 & -1 & 0.286 & 1.826 & 0.039 & 0.101 & 1.68 & 0.26 & 0.24 & 0.200 & 0.000471 & 4545.1 & 0.172 \\
\hline
\end{tabular}


Table 2 (cont'd). Experimental design matrix with the factors and responses of A356 alloy model 1

\begin{tabular}{|c|c|c|c|c|c|c|c|c|c|c|c|c|c|c|c|c|c|c|c|}
\hline \multirow{2}{*}{ No } & \multicolumn{8}{|c|}{ Coded values } & \multicolumn{8}{|c|}{ Actual values } & \multicolumn{3}{|c|}{ Response } \\
\hline & $\mathrm{A}$ & $\mathrm{B}$ & $\mathrm{C}$ & $\mathrm{D}$ & $\mathrm{E}$ & $\mathrm{F}$ & G & $\mathrm{H}$ & $\mathrm{LC} 1$ & WC1 & $\mathrm{HCl}$ & WiCl & WC2 & LC2 & $\mathrm{BC} 2$ & TWOM & $\mathrm{VC1}$ & DC1 & WL \\
\hline 40 & -1 & 1 & -1 & 1 & -1 & -1 & 1 & -1 & 0.282 & 1.998 & 0.036 & 0.101 & 1.68 & 0.26 & 0.241 & 0.200 & 0.000446 & 4271.1 & 0.13 \\
\hline 41 & -1 & -1 & 1 & 1 & -1 & -1 & 1 & 1 & 0.282 & 1.826 & 0.039 & 0.101 & 1.68 & 0.26 & 0.241 & 0.285 & 0.000381 & 5379.9 & 0.146 \\
\hline 42 & 1 & 1 & -1 & -1 & -1 & -1 & 1 & 1 & 0.286 & 1.998 & 0.036 & 0.097 & 1.68 & 0.26 & 0.241 & 0.285 & 0.000471 & 4545.1 & 0.172 \\
\hline 43 & 1 & -1 & 1 & 1 & -1 & 1 & -1 & 1 & 0.286 & 1.826 & 0.039 & 0.101 & 1.68 & 0.264 & 0.24 & 0.285 & 0.000446 & 4271.1 & 0.13 \\
\hline 44 & -1 & -1 & 1 & -1 & -1 & -1 & -1 & 1 & 0.282 & 1.826 & 0.039 & 0.097 & 1.68 & 0.26 & 0.24 & 0.285 & 0.000381 & 5379.9 & 0.146 \\
\hline 45 & -1 & 1 & 1 & 1 & -1 & 1 & -1 & 1 & 0.282 & 1.998 & 0.039 & 0.101 & 1.68 & 0.264 & 0.24 & 0.285 & 0.000471 & 4545.1 & 0.172 \\
\hline 46 & -1 & -1 & 1 & -1 & 1 & 1 & -1 & 1 & 0.282 & 1.826 & 0.039 & 0.097 & 1.83 & 0.264 & 0.24 & 0.285 & 0.000446 & 4271.1 & 0.13 \\
\hline 47 & -1 & 1 & 1 & -1 & 1 & -1 & 1 & 1 & 0.282 & 1.998 & 0.039 & 0.097 & 1.83 & 0.26 & 0.241 & 0.285 & 0.000381 & 5379.9 & 0.146 \\
\hline 48 & -1 & 1 & -1 & -1 & -1 & 1 & -1 & 1 & 0.282 & 1.998 & 0.036 & 0.097 & 1.68 & 0.264 & 0.24 & 0.285 & 0.000471 & 4545.1 & 0.172 \\
\hline 49 & -1 & 1 & -1 & -1 & 1 & 1 & -1 & -1 & 0.282 & 1.998 & 0.036 & 0.097 & 1.83 & 0.264 & 0.24 & 0.200 & 0.000446 & 4271.1 & 0.13 \\
\hline 50 & 0 & 0 & 0 & 0 & 0 & 0 & 0 & 0 & 0.284 & 1.912 & 0.0375 & 0.099 & 1.755 & 0.262 & 0.241 & 0.242 & 0.000381 & 5379.9 & 0.146 \\
\hline 51 & 1 & -1 & 1 & -1 & -1 & -1 & 1 & -1 & 0.286 & 1.826 & 0.039 & 0.097 & 1.68 & 0.26 & 0.241 & 0.200 & 0.000471 & 4545.1 & 0.172 \\
\hline 52 & 1 & -1 & -1 & -1 & -1 & 1 & -1 & 1 & 0.286 & 1.826 & 0.036 & 0.097 & 1.68 & 0.264 & 0.24 & 0.285 & 0.000446 & 4271.1 & 0.13 \\
\hline 53 & -1 & -1 & -1 & 1 & 1 & -1 & -1 & -1 & 0.282 & 1.826 & 0.036 & 0.101 & 1.83 & 0.26 & 0.24 & 0.200 & 0.000381 & 5379.9 & 0.146 \\
\hline 54 & -1 & -1 & -1 & 1 & -1 & 1 & -1 & -1 & 0.282 & 1.826 & 0.036 & 0.101 & 1.68 & 0.264 & 0.24 & 0.200 & 0.000471 & 4545.1 & 0.172 \\
\hline 55 & 1 & -1 & -1 & 1 & -1 & 1 & 1 & 1 & 0.286 & 1.826 & 0.036 & 0.101 & 1.68 & 0.264 & 0.241 & 0.285 & 0.000446 & 4271.1 & 0.13 \\
\hline 56 & 1 & 1 & 1 & -1 & 1 & -1 & -1 & -1 & 0.286 & 1.998 & 0.039 & 0.097 & 1.83 & 0.26 & 0.24 & 0.200 & 0.000381 & 5379.9 & 0.146 \\
\hline 57 & -1 & -1 & 1 & 1 & 1 & -1 & 1 & -1 & 0.282 & 1.826 & 0.039 & 0.101 & 1.83 & 0.26 & 0.241 & 0.200 & 0.000471 & 4545.1 & 0.172 \\
\hline 58 & 1 & -1 & -1 & -1 & -1 & -1 & -1 & -1 & 0.286 & 1.826 & 0.036 & 0.097 & 1.68 & 0.26 & 0.24 & 0.200 & 0.000446 & 4271.1 & 0.13 \\
\hline 59 & -1 & 1 & 1 & 1 & 1 & 1 & -1 & -1 & 0.282 & 1.998 & 0.039 & 0.101 & 1.83 & 0.264 & 0.24 & 0.200 & 0.000381 & 5379.9 & 0.146 \\
\hline 60 & 1 & 1 & 1 & -1 & 1 & 1 & -1 & 1 & 0.286 & 1.998 & 0.039 & 0.097 & 1.83 & 0.264 & 0.24 & 0.285 & 0.000471 & 4545.1 & 0.172 \\
\hline 61 & 1 & -1 & 1 & 1 & 1 & -1 & -1 & 1 & 0.286 & 1.826 & 0.039 & 0.101 & 1.83 & 0.26 & 0.24 & 0.285 & 0.000446 & 4271.1 & 0.13 \\
\hline 62 & 1 & 1 & -1 & 1 & -1 & -1 & -1 & 1 & 0.286 & 1.998 & 0.036 & 0.101 & 1.68 & 0.26 & 0.24 & 0.285 & 0.000381 & 5379.9 & 0.146 \\
\hline 63 & -1 & 1 & 1 & -1 & -1 & 1 & 1 & 1 & 0.282 & 1.998 & 0.039 & 0.097 & 1.68 & 0.264 & 0.241 & 0.285 & 0.000471 & 4545.1 & 0.172 \\
\hline 64 & -1 & -1 & -1 & -1 & -1 & -1 & 1 & 1 & 0.282 & 1.826 & 0.036 & 0.097 & 1.68 & 0.26 & 0.241 & 0.285 & 0.000446 & 4271.1 & 0.13 \\
\hline 65 & -1 & 1 & 1 & 1 & 1 & -1 & -1 & 1 & 0.282 & 1.998 & 0.039 & 0.101 & 1.83 & 0.26 & 0.24 & 0.285 & 0.000381 & 5379.9 & 0.146 \\
\hline 66 & 0 & 0 & 0 & 0 & 0 & 0 & 0 & 0 & 0.284 & 1.912 & 0.0375 & 0.099 & 1.755 & 0.262 & 0.2405 & 0.242 & 0.000471 & 4545.1 & 0.172 \\
\hline 67 & 1 & 1 & 1 & -1 & -1 & 1 & -1 & -1 & 0.286 & 1.998 & 0.039 & 0.097 & 1.68 & 0.264 & 0.24 & 0.200 & 0.000446 & 4271.1 & 0.13 \\
\hline 68 & -1 & 1 & -1 & 1 & 1 & 1 & 1 & -1 & 0.282 & 1.998 & 0.036 & 0.101 & 1.83 & 0.264 & 0.241 & 0.200 & 0.000381 & 5379.9 & 0.146 \\
\hline 69 & -1 & -1 & 1 & 1 & 1 & 1 & 1 & 1 & 0.282 & 1.826 & 0.039 & 0.101 & 1.83 & 0.264 & 0.241 & 0.285 & 0.000471 & 4545.1 & 0.172 \\
\hline 70 & -1 & -1 & -1 & 1 & 1 & 1 & -1 & 1 & 0.282 & 1.826 & 0.036 & 0.101 & 1.83 & 0.264 & 0.24 & 0.285 & 0.000446 & 4271.1 & 0.13 \\
\hline 71 & 1 & 1 & -1 & 1 & -1 & 1 & -1 & -1 & 0.286 & 1.998 & 0.036 & 0.101 & 1.68 & 0.264 & 0.24 & 0.200 & 0.000381 & 5379.9 & 0.146 \\
\hline 72 & -1 & -1 & -1 & -1 & 1 & -1 & 1 & -1 & 0.282 & 1.826 & 0.036 & 0.097 & 1.83 & 0.26 & 0.241 & 0.200 & 0.000471 & 4545.1 & 0.172 \\
\hline 73 & 0 & 0 & 0 & 0 & 2.828 & 0 & 0 & 0 & 0.284 & 1.912 & 0.0375 & 0.099 & 1.9671 & 0.262 & 0.2405 & 0.242 & 0.000446 & 4271.1 & 0.13 \\
\hline 74 & 0 & 0 & 0 & 0 & 0 & 0 & -2.828 & 0 & 0.284 & 1.912 & 0.0375 & 0.099 & 1.755 & 0.262 & 0.2391 & 0.242 & 0.000381 & 5379.9 & 0.146 \\
\hline 75 & 0 & 2.828 & 0 & 0 & 0 & 0 & 0 & 0 & 0.284 & 2.1552 & 0.0375 & 0.099 & 1.755 & 0.262 & 0.2405 & 0.242 & 0.000471 & 4545.1 & 0.172 \\
\hline 76 & 0 & 0 & 0 & 0 & 0 & 0 & 0 & 0 & 0.284 & 1.912 & 0.0375 & 0.099 & 1.755 & 0.262 & 0.2405 & 0.242 & 0.000446 & 4271.1 & 0.13 \\
\hline
\end{tabular}

e-ISSN: 2289-7771

\section{JAGPE}


Table 2 (cont'd). Experimental design matrix with the factors and responses of A356 alloy model 1

\begin{tabular}{|c|c|c|c|c|c|c|c|c|c|c|c|c|c|c|c|c|c|c|c|}
\hline \multirow{2}{*}{ No } & \multicolumn{8}{|c|}{ Coded values } & \multicolumn{8}{|c|}{ Actual values } & \multicolumn{3}{|c|}{ Response } \\
\hline & $\mathrm{A}$ & B & $\mathrm{C}$ & $\mathrm{D}$ & $E$ & $\mathrm{~F}$ & G & $\mathrm{H}$ & LC1 & WC1 & $\mathrm{HCl}$ & WiCl & WC2 & LC2 & $\mathrm{BC} 2$ & TWOM & $\mathrm{VCl}$ & DC1 & WL \\
\hline 77 & 0 & -2.828 & 0 & 0 & 0 & 0 & 0 & 0 & 0.284 & 1.6688 & 0.0375 & 0.099 & 1.755 & 0.262 & 0.2405 & 0.242 & 0.000381 & 5379.9 & 0.146 \\
\hline 78 & 0 & 0 & 0 & 0 & -2.828 & 0 & 0 & 0 & 0.284 & 1.912 & 0.0375 & 0.099 & 1.5429 & 0.262 & 0.2405 & 0.242 & 0.000471 & 4545.1 & 0.172 \\
\hline 79 & 0 & 0 & 0 & 0 & 0 & 2.828 & 0 & 0 & 0.284 & 1.912 & 0.0375 & 0.099 & 1.755 & 0.2677 & 0.2405 & 0.242 & 0.000446 & 4271.1 & 0.13 \\
\hline 80 & 0 & 0 & 0 & 2.828 & 0 & 0 & 0 & 0 & 0.284 & 1.912 & 0.0375 & 0.1047 & 1.755 & 0.262 & 0.2405 & 0.242 & 0.000381 & 5379.9 & 0.146 \\
\hline 81 & 0 & 0 & 0 & 0 & 0 & 0 & 0 & -2.828 & 0.284 & 1.912 & 0.0375 & 0.099 & 1.755 & 0.262 & 0.2405 & 0.122 & 0.000471 & 4545.1 & 0.172 \\
\hline 82 & 0 & 0 & 0 & 0 & 0 & -2.828 & 0 & 0 & 0.284 & 1.912 & 0.0375 & 0.099 & 1.755 & 0.2563 & 0.2405 & 0.242 & 0.000446 & 4271.1 & 0.13 \\
\hline 83 & 0 & 0 & 0 & -2.828 & 0 & 0 & 0 & 0 & 0.284 & 1.912 & 0.0375 & 0.0933 & 1.755 & 0.262 & 0.2405 & 0.242 & 0.000381 & 5379.9 & 0.146 \\
\hline 84 & 2.828 & 0 & 0 & 0 & 0 & 0 & 0 & 0 & 0.2897 & 1.912 & 0.0375 & 0.099 & 1.755 & 0.262 & 0.2405 & 0.242 & 0.000471 & 4545.1 & 0.172 \\
\hline 85 & 0 & 0 & 0 & 0 & 0 & 0 & 2.828 & 0 & 0.284 & 1.912 & 0.0375 & 0.099 & 1.755 & 0.262 & 0.2419 & 0.242 & 0.000446 & 4271.1 & 0.13 \\
\hline 86 & 0 & 0 & 0 & 0 & 0 & 0 & 0 & 0 & 0.284 & 1.912 & 0.0375 & 0.099 & 1.755 & 0.262 & 0.2405 & 0.242 & 0.000381 & 5379.9 & 0.146 \\
\hline 87 & 0 & 0 & -2.828 & 0 & 0 & 0 & 0 & 0 & 0.284 & 1.912 & 0.0333 & 0.099 & 1.755 & 0.262 & 0.2405 & 0.242 & 0.000471 & 4545.1 & 0.172 \\
\hline 88 & 0 & 0 & 0 & 0 & 0 & 0 & 0 & 2.828 & 0.284 & 1.912 & 0.0375 & 0.099 & 1.755 & 0.262 & 0.2405 & 0.363 & 0.000446 & 4271.1 & 0.13 \\
\hline 89 & 0 & 0 & 2.828 & 0 & 0 & 0 & 0 & 0 & 0.284 & 1.912 & 0.0417 & 0.099 & 1.755 & 0.262 & 0.2405 & 0.242 & 0.000381 & 5379.9 & 0.146 \\
\hline 90 & -2.828 & 0 & 0 & 0 & 0 & 0 & 0 & 0 & 0.278 & 1.912 & 0.0375 & 0.099 & 1.755 & 0.262 & 0.2405 & 0.242 & 0.000471 & 4545.1 & 0.172 \\
\hline
\end{tabular}

Table 3. Regression coefficients values for volume of cast 1, density of cast 1 and weight loss

\begin{tabular}{|c|c|c|c|c|c|c|c|c|c|c|c|c|}
\hline \multirow[b]{2}{*}{ Term } & \multicolumn{4}{|c|}{ Volume of cast 1} & \multicolumn{4}{|c|}{ Density of cast 1} & \multicolumn{4}{|c|}{ Weight loss } \\
\hline & Coef & SE Coef & $\mathrm{T}$ & $\mathrm{P}$ & Coef & SE Coef & $\mathrm{T}$ & $\mathrm{P}$ & Coef & SE Coef & $\mathrm{T}$ & $\mathrm{P}$ \\
\hline Constant & -0.86429 & 0.9139 & -0.946 & 0.349 & 10853667 & 11322215 & 0.959 & 0.343 & -60.83 & 414.07 & -0.147 & 0.884 \\
\hline LC1 & 0.38624 & 1.2308 & 0.314 & 0.755 & -7383205 & 15248347 & -0.484 & 0.631 & -142.18 & 557.65 & -0.255 & 0.8 \\
\hline WC1 & 0.01099 & 0.0275 & 0.4 & 0.691 & 86750 & 340232 & 0.255 & 0.8 & 15.77 & 12.44 & 1.267 & 0.212 \\
\hline $\mathrm{HC} 1$ & 1.67082 & 1.575 & 1.061 & 0.294 & -27061209 & 19512201 & -1.387 & 0.172 & -289.4 & 713.59 & -0.406 & 0.687 \\
\hline $\mathrm{WiC} 1$ & -0.03884 & 1.1859 & -0.033 & 0.974 & 6342051 & 14692614 & 0.432 & 0.668 & 388.18 & 537.33 & 0.722 & 0.474 \\
\hline WC2 & 0.00534 & 0.0315 & 0.17 & 0.866 & -192949 & 390178 & -0.495 & 0.623 & -8.03 & 14.27 & -0.563 & 0.576 \\
\hline LC2 & 0.70117 & 1.2233 & 0.573 & 0.569 & -18085559 & 15155569 & -1.193 & 0.239 & -570.75 & 554.26 & -1.03 & 0.309 \\
\hline $\mathrm{BC} 2$ & 5.56721 & 6.702 & 0.831 & 0.411 & -58874358 & 83032283 & -0.709 & 0.482 & 1125.21 & 3036.62 & 0.371 & 0.713 \\
\hline TWOM & 0.02099 & 0.0554 & 0.378 & 0.707 & -468846 & 686962 & -0.682 & 0.498 & -12.24 & 25.12 & -0.487 & 0.628 \\
\hline $\mathrm{LC} 1 * \mathrm{LC} 1$ & 1.39258 & 0.8374 & 1.663 & 0.103 & -6790938 & 10374608 & -0.655 & 0.516 & 811.33 & 379.41 & 2.138 & 0.038 \\
\hline $\mathrm{WC} 1 * \mathrm{WC} 1$ & -0.00001 & 0.0005 & -0.016 & 0.987 & 3382 & 5611 & 0.603 & 0.55 & 0.22 & 0.21 & 1.068 & 0.291 \\
\hline $\mathrm{HC} 1$ * $\mathrm{HC} 1$ & -0.02431 & 1.4887 & -0.016 & 0.987 & 11116111 & 18443748 & 0.603 & 0.55 & 720.14 & 674.52 & 1.068 & 0.2911 \\
\hline $\mathrm{WiC} 1 * \mathrm{WiC} 1$ & -1.41992 & 0.8374 & -1.696 & 0.097 & 19296562 & 10374608 & 1.86 & 0.069 & -1.17 & 379.41 & -0.003 & 0.998 \\
\hline $\mathrm{WC} 2 * \mathrm{WC} 2$ & 0.00071 & 0.0006 & 1.197 & 0.238 & -7874 & 7377 & -1.067 & 0.292 & 0.12 & 0.27 & 0.45 & 0.655 \\
\hline $\mathrm{LC} 2 * \mathrm{LC} 2$ & 0.61133 & 0.8374 & 0.73 & 0.469 & -15353438 & 10374608 & -1.48 & 0.146 & -469.92 & 379.41 & -1.239 & 0.222 \\
\hline $\mathrm{BC} 2 * \mathrm{BC} 2$ & -6.46875 & 13.3984 & -0.483 & 0.632 & 31545000 & 165993734 & 0.19 & 0.85 & -3768.75 & 6070.64 & -0.621 & 0.538 \\
\hline TWOM*TWOM & 0.00221 & 0.0019 & 1.197 & 0.238 & -24462 & 22921 & -1.067 & 0.292 & 0.38 & 0.84 & 0.45 & 0.655 \\
\hline
\end{tabular}


Table 4. ANOVA Table for volume of cast 1, density of cast 1 and weight loss

\begin{tabular}{|c|c|c|c|c|c|c|c|c|c|c|c|c|c|c|c|c|}
\hline \multirow[b]{2}{*}{ Source } & \multirow[b]{2}{*}{ DF } & \multicolumn{5}{|c|}{ Volume of cast 1} & \multicolumn{5}{|c|}{ Density of cast 1} & \multicolumn{5}{|c|}{ Weight loss } \\
\hline & & Seq SS & $\begin{array}{l}\text { Adj } \\
\text { SS }\end{array}$ & $\begin{array}{l}\text { Adj } \\
\text { MS }\end{array}$ & $\mathrm{F}$ & $\mathrm{P}$ & Seq SS & $\begin{array}{l}\text { Adj } \\
\text { SS }\end{array}$ & $\begin{array}{l}\text { Adj } \\
\text { MS }\end{array}$ & $\mathrm{F}$ & $\mathrm{P}$ & Seq SS & $\begin{array}{l}\text { Adj } \\
\text { SS }\end{array}$ & $\begin{array}{l}\text { Adj } \\
\text { MS }\end{array}$ & $\mathrm{F}$ & $\mathrm{P}$ \\
\hline Regression & 44 & 0.000000 & 0.000000 & 0.000000 & 1.23 & 0.245 & 10996398 & 10996398 & 249918 & 1.25 & 0.232 & 0.013759 & 0.013759 & 0.000313 & 1.17 & 0.304 \\
\hline Linear & 8 & 0.000000 & 0.000000 & 0.000000 & 0.28 & 0.969 & 2571173 & 920926 & 115116 & 0.57 & 0.793 & 0.003058 & 0.001158 & 0.000145 & 0.54 & 0.820 \\
\hline LC1 & 1 & 0.000000 & 0.000000 & 0.000000 & 0.10 & 0.755 & 35381 & 46981 & 46981 & 0.23 & 0.631 & 0.000505 & 0.000017 & 0.000017 & 0.07 & 0.800 \\
\hline WC1 & 1 & 0.000000 & 0.000000 & 0.000000 & 0.16 & 0.691 & 364558 & 13028 & 13028 & 0.07 & 0.8 & 0.000398 & 0.000430 & 0.000430 & 1.61 & 0.212 \\
\hline $\mathrm{HC} 1$ & 1 & 0.000000 & 0.000000 & 0.000000 & 1.13 & 0.294 & 575210 & 385445 & 385445 & 1.92 & 0.172 & 0.000229 & 0.000044 & 0.000044 & 0.16 & 0.687 \\
\hline WiCl & 1 & 0.000000 & 0.000000 & 0.000000 & 0.00 & 0.974 & 35381 & 37337 & 37337 & 0.19 & 0.668 & 0.000505 & 0.000140 & 0.000140 & 0.52 & 0.474 \\
\hline WC2 & 1 & 0.000000 & 0.000000 & 0.000000 & 0.03 & 0.866 & 714460 & 49005 & 49005 & 0.24 & 0.623 & 0.000644 & 0.000085 & 0.000085 & 0.32 & 0.576 \\
\hline LC2 & 1 & 0.000000 & 0.000000 & 0.000000 & 0.33 & 0.569 & 555378 & 285365 & 285365 & 1.42 & 0.239 & 0.000044 & 0.000284 & 0.000284 & 1.06 & 0.309 \\
\hline $\mathrm{BC} 2$ & 1 & 0.000000 & 0.000000 & 0.000000 & 0.69 & 0.411 & 290232 & 100749 & 100749 & 0.5 & 0.482 & 0.000314 & 0.000037 & 0.000037 & 0.14 & 0.713 \\
\hline TWOM & 1 & 0.000000 & 0.000000 & 0.000000 & 0.14 & 0.707 & 573 & 93342 & 93342 & 0.47 & 0.498 & 0.000418 & 0.000064 & 0.000064 & 0.24 & 0.628 \\
\hline Square & 8 & 0.000000 & 0.000000 & 0.000000 & 1.22 & 0.307 & 1997473 & 1997473 & 249684 & 1.25 & 0.295 & 0.002526 & 0.002526 & 0.000316 & 1.18 & 0.333 \\
\hline LC $1 *$ LC1 & 1 & 0.000000 & 0.000000 & 0.000000 & 2.77 & 0.103 & 83538 & 85861 & 85861 & 0.43 & 0.516 & 0.001192 & 0.001226 & 0.001226 & 4.57 & 0.038 \\
\hline $\mathrm{WC} 1 * \mathrm{WC} 1$ & 1 & 0.000000 & 0.000000 & 0.000000 & 0.00 & 0.987 & 91142 & 72793 & 72793 & 0.36 & 0.55 & 0.000312 & 0.000306 & 0.000306 & 1.14 & 0.291 \\
\hline $\mathrm{HCl} 1 * \mathrm{HC} 1$ & 1 & 0.000000 & 0.000000 & 0.000000 & 0.00 & 0.987 & 103294 & 72793 & 72793 & 0.36 & 0.55 & 0.000354 & 0.000306 & 0.000306 & 1.14 & 0.291 \\
\hline $\mathrm{WiC} 1 * \mathrm{WiC} 1$ & 1 & 0.000000 & 0.000000 & 0.000000 & 2.88 & 0.097 & 911254 & 693262 & 693262 & 3.46 & 0.069 & 0.000001 & 0.000000 & 0.000000 & 0.00 & 0.998 \\
\hline $\mathrm{WC} 2 * \mathrm{WC} 2$ & 1 & 0.000000 & 0.000000 & 0.000000 & 1.43 & 0.238 & 160650 & 228247 & 228247 & 1.14 & 0.292 & 0.000085 & 0.000054 & 0.000054 & 0.20 & 0.655 \\
\hline $\mathrm{LC} 2 * \mathrm{LC} 2$ & 1 & 0.000000 & 0.000000 & 0.000000 & 0.53 & 0.469 & 402698 & 438883 & 438883 & 2.19 & 0.146 & 0.000408 & 0.000411 & 0.000411 & 1.53 & 0.222 \\
\hline $\mathrm{BC} 2 * \mathrm{BC} 2$ & 1 & 0.000000 & 0.000000 & 0.000000 & 0.23 & 0.632 & 16650 & 7237 & 7237 & 0.04 & 0.85 & 0.000118 & 0.000103 & 0.000103 & 0.39 & 0.538 \\
\hline TWOM*TWOM & 1 & 0.000000 & 0.000000 & 0.000000 & 1.43 & 0.238 & 228247 & 228247 & 228247 & 1.14 & 0.292 & 0.000054 & 0.000054 & 0.000054 & 0.20 & 0.655 \\
\hline Interaction & 28 & 0.000000 & 0.000000 & 0.000000 & 1.01 & 0.473 & 6427752 & 6427752 & 229563 & 1.15 & 0.335 & 0.008175 & 0.008175 & 0.000292 & 1.09 & 0.391 \\
\hline $\mathrm{LC} 1 * \mathrm{WC} 1$ & 1 & 0.000000 & 0.000000 & 0.000000 & 0.05 & 0.823 & 19210 & 19210 & 19210 & 0.10 & 0.758 & 0.000004 & 0.000004 & 0.000004 & 0.01 & 0.909 \\
\hline $\mathrm{LC} 1 * \mathrm{HC} 1$ & 1 & 0.000000 & 0.000000 & 0.000000 & 0.46 & 0.503 & 172890 & 172890 & 172890 & 0.86 & 0.358 & 0.000032 & 0.000032 & 0.000032 & 0.12 & 0.733 \\
\hline LC ${ }^{*}$ WiC 1 & 1 & 0.000000 & 0.000000 & 0.000000 & 0.25 & 0.618 & 234546 & 234546 & 234546 & 1.17 & 0.285 & 0.000252 & 0.000252 & 0.000252 & 0.94 & 0.337 \\
\hline $\mathrm{LC} 1 * \mathrm{WC} 2$ & 1 & 0.000000 & 0.000000 & 0.000000 & 0.72 & 0.401 & 120617 & 120617 & 120617 & 0.60 & 0.442 & 0.000021 & 0.000021 & 0.000021 & 0.08 & 0.779 \\
\hline $\mathrm{LC} 1 * \mathrm{LC} 2$ & 1 & 0.000000 & 0.000000 & 0.000000 & 1.04 & 0.313 & 77729 & 77729 & 77729 & 0.39 & 0.537 & 0.000221 & 0.000221 & 0.000221 & 0.83 & 0.368 \\
\hline $\mathrm{LC} 1 * \mathrm{BC} 2$ & 1 & 0.000000 & 0.000000 & 0.000000 & 0.72 & 0.401 & 120617 & 120617 & 120617 & 0.60 & 0.442 & 0.000021 & 0.000021 & 0.000021 & 0.08 & 0.779 \\
\hline LC1*TWOM & 1 & 0.000000 & 0.000000 & 0.000000 & 0.16 & 0.693 & 4914 & 4914 & 4914 & 0.02 & 0.876 & 0.00007 & 0.00007 & 0.00007 & 0.26 & 0.611 \\
\hline $\mathrm{WC} 1 * \mathrm{HC} 1$ & 1 & 0.000000 & 0.000000 & 0.000000 & 0.16 & 0.693 & 4914 & 4914 & 4914 & 0.02 & 0.876 & 0.00007 & 0.00007 & 0.00007 & 0.26 & 0.611 \\
\hline $\mathrm{WC} 1 * \mathrm{WiC} 1$ & 1 & 0.000000 & 0.000000 & 0.000000 & 7.37 & 0.009 & 947508 & 947508 & 947508 & 4.73 & 0.035 & 0.000582 & 0.000582 & 0.000582 & 2.17 & 0.148 \\
\hline $\mathrm{WC} 1 * \mathrm{WC} 2$ & 1 & 0.000000 & 0.000000 & 0.000000 & 1.87 & 0.179 & 20107 & 20107 & 20107 & 0.10 & 0.753 & 0.001251 & 0.001251 & 0.001251 & 4.67 & 0.036 \\
\hline $\mathrm{WC} 1 * \mathrm{LC} 2$ & 1 & 0.000000 & 0.000000 & 0.000000 & 0.16 & 0.693 & 4914 & 4914 & 4914 & 0.02 & 0.876 & 0.00007 & 0.00007 & 0.00007 & 0.26 & 0.611 \\
\hline WC $1 * \mathrm{BC} 2$ & 1 & 0.000000 & 0.000000 & 0.000000 & 0.01 & 0.904 & 75955 & 75955 & 75955 & 0.38 & 0.541 & 0.000501 & 0.000501 & 0.000501 & 1.87 & 0.179 \\
\hline WC1*TWOM & 1 & 0.000000 & 0.000000 & 0.000000 & 0.84 & 0.364 & 18333 & 18333 & 18333 & 0.09 & 0.764 & 0.001531 & 0.001531 & 0.001531 & 5.71 & 0.021 \\
\hline $\mathrm{HC} 1 * \mathrm{WiC} 1$ & 1 & 0.000000 & 0.000000 & 0.000000 & 0.05 & 0.823 & 19210 & 19210 & 19210 & 0.10 & 0.758 & 0.000004 & 0.000004 & 0.000004 & 0.01 & 0.909 \\
\hline $\mathrm{HC} 1 * \mathrm{WC} 2$ & 1 & 0.000000 & 0.000000 & 0.000000 & 0.05 & 0.823 & 19210 & 19210 & 19210 & 0.10 & 0.758 & 0.000004 & 0.000004 & 0.000004 & 0.01 & 0.909 \\
\hline $\mathrm{HC} 1 * \mathrm{LC} 2$ & 1 & 0.000000 & 0.000000 & 0.000000 & 0.91 & 0.347 & 579882 & 579882 & 579882 & 2.89 & 0.096 & 0.000385 & 0.000385 & 0.000385 & 1.44 & 0.237 \\
\hline $\mathrm{HC} 1 * \mathrm{BC} 2$ & 1 & 0.000000 & 0.000000 & 0.000000 & 2.48 & 0.122 & 941288 & 941288 & 941288 & 4.70 & 0.036 & 0.000172 & 0.000172 & 0.000172 & 0.64 & 0.427 \\
\hline HC1*TWOM & 1 & 0.000000 & 0.000000 & 0.000000 & 0.46 & 0.503 & 172890 & 172890 & 172890 & 0.86 & 0.358 & 0.000032 & 0.000032 & 0.000032 & 0.12 & 0.733 \\
\hline $\mathrm{WiC} 1 * \mathrm{WC} 2$ & 1 & 0.000000 & 0.000000 & 0.000000 & 1.68 & 0.201 & 390000 & 390000 & 390000 & 1.95 & 0.17 & 0.000001 & 0.000001 & 0.000001 & 0.00 & 0.958 \\
\hline WiC $1 *$ LC 2 & 1 & 0.000000 & 0.000000 & 0.000000 & 0.33 & 0.571 & 3 & 3 & 3 & 0.00 & 0.997 & 0.000347 & 0.000347 & 0.000347 & 1.29 & 0.261 \\
\hline $\mathrm{WiC} 1 * \mathrm{BC} 2$ & 1 & 0.000000 & 0.000000 & 0.000000 & 0.00 & 0.959 & 42890 & 42890 & 42890 & 0.21 & 0.646 & 0.000147 & 0.000147 & 0.000147 & 0.55 & 0.463 \\
\hline
\end{tabular}


Table 4 (cont'd). ANOVA Table for volume of cast 1 , density of cast 1 and weight loss

\begin{tabular}{|c|c|c|c|c|c|c|c|c|c|c|c|c|c|c|c|c|}
\hline \multirow[b]{2}{*}{ Source } & \multirow[b]{2}{*}{ DF } & \multicolumn{5}{|c|}{ Volume of cast 1} & \multicolumn{5}{|c|}{ Density of cast 1} & \multicolumn{5}{|c|}{ Weight loss } \\
\hline & & Seq SS & $\begin{array}{l}\text { Adj } \\
\text { SS }\end{array}$ & $\begin{array}{l}\text { Adj } \\
\text { MS }\end{array}$ & $\mathrm{F}$ & $\mathrm{P}$ & Seq SS & $\begin{array}{l}\text { Adj } \\
\text { SS }\end{array}$ & $\begin{array}{l}\text { Adj } \\
\text { MS }\end{array}$ & $\mathrm{F}$ & $\mathrm{P}$ & Seq SS & $\begin{array}{l}\text { Adj } \\
\text { SS }\end{array}$ & $\begin{array}{l}\text { Adj } \\
\text { MS }\end{array}$ & $\mathrm{F}$ & $\mathrm{P}$ \\
\hline WiC1*TWOM & 1 & 0.000000 & 0.000000 & 0.000000 & 0.91 & 0.347 & 579882 & 579882 & 579882 & 2.89 & 0.096 & 0.000385 & 0.000385 & 0.000385 & 1.44 & 0.237 \\
\hline WC $2 *$ LC2 & 1 & 0.000000 & 0.000000 & 0.000000 & 0.05 & 0.823 & 19210 & 19210 & 19210 & 0.10 & 0.758 & 0.000004 & 0.000004 & 0.000004 & 0.01 & 0.909 \\
\hline $\mathrm{WC} 2 * \mathrm{BC} 2$ & 1 & 0.000000 & 0.000000 & 0.000000 & 0.00 & 0.959 & 42890 & 42890 & 42890 & 0.21 & 0.646 & 0.000147 & 0.000147 & 0.000147 & 0.55 & 0.463 \\
\hline WC $2 *$ TWOM & 1 & 0.000000 & 0.000000 & 0.000000 & 0.25 & 0.618 & 234546 & 234546 & 234546 & 1.17 & 0.285 & 0.000252 & 0.000252 & 0.000252 & 0.94 & 0.337 \\
\hline $\mathrm{LC} 2 * \mathrm{BC} 2$ & 1 & 0.000000 & 0.000000 & 0.000000 & 0.61 & 0.44 & 688900 & 688900 & 688900 & 3.44 & 0.07 & 0.000893 & 0.000893 & 0.000893 & 3.33 & 0.075 \\
\hline LC2*TWOM & 1 & 0.000000 & 0.000000 & 0.000000 & 5.13 & 0.028 & 484694 & 484694 & 484694 & 2.42 & 0.127 & 0.000777 & 0.000777 & 0.000777 & 2.90 & 0.096 \\
\hline BC2*TWOM & 1 & 0.000000 & 0.000000 & 0.000000 & 1.68 & 0.201 & 390000 & 390000 & 390000 & 1.95 & 0.17 & 0.000001 & 0.000001 & 0.000001 & 0.00 & 0.958 \\
\hline Residual Error & 45 & 0.000000 & 0.000000 & 0.000000 & & & 9017647 & 9017647 & 200392 & & & 0.012061 & 0.012061 & 0.000268 & & \\
\hline Lack-of-Fit & 36 & 0.000000 & 0.000000 & 0.000000 & 0.82 & 0.687 & 6432973 & 6432973 & 178694 & 0.62 & 0.85 & 0.009815 & 0.009815 & 0.000273 & 1.09 & 0.477 \\
\hline Pure Error & 9 & 0.000000 & 0.000000 & 0.000000 & & & 2584674 & 2584674 & 287186 & & & 0.002246 & 0.002246 & 0.00025 & & \\
\hline Total & 89 & 0.000000 & & & & & 20014045 & & & & & 0.02582 & & & & \\
\hline
\end{tabular}




\subsection{A356 alloy}

From the regression analysis shown below in Table 3, two factors $\mathrm{WC} 1 * \mathrm{WiC} 1$ and TWOM*LC2 were statistically significant to the response (volume of cast 1) because their $p$-values which are 0.009 and 0.029 respectively are less than 0.05 . These values were obtained during the analysis of the interactions of the constituent variables of the system. It means that if the factors in the casting process have more than $95 \%$ confidence level, that is $\mathrm{p}<0.05$, they are regarded to have an extremely significant effect on the casting efficiency in the melt shop. However, the values 0.009 and 0.029 refer to $99.1 \%$ confidence level and $95 \%$ confidence level, respectively. The model shows that $54.63 \%$ in light output which is the R-sq value, the model is also overfitted because the $R$-sq(pred) is $0.00 \%$. The ANOVA table of Volume of cast 1 in Table 4 shows that the regression $f$-value of 1.23, a low significance for the regression model and also shows that linear regression, square and the intersection of A356 alloy model are insignificant.

In Table 3, two factors are also statistically significant to the response (density of cast 1$) \mathrm{WC} 1 * \mathrm{WiC} 1$ and $\mathrm{HC} 1 * \mathrm{BC} 2$ with values of 0.035 and 0.036 , respectively. The $R$-sq value shows that the model is $54.94 \%$ in light output and it is overfitted due to the $0.00 \%$ value of $R$-sq(pred). The regression $f$-value of 1.25 in the ANOVA table (Table 3) shows that the regression model has low significance. It also shows that the linear, square and interaction are insignificant. For the regression analysis, considering the response (weight loss) in Table 3, the model is $53.29 \%$ in light output and it is also overfitting; three factors LC1 *C1, $^{2}$ $\mathrm{WC} 1 * \mathrm{WC} 2$ and $\mathrm{TWOM} * \mathrm{WiC} 2$ are statistically significant with $p$-values of $0.038,0.036$ and 0.021 , respectively. The linear, square and interaction in Table 3 are also insignificant. The regression model of the weight loss also has a low significance with regression $f$-value of 1.17. Figures 1(a), 1(b) and 1(c) show the residual plots for volume of cast 1, density of cast and weight loss respectively of A356 alloy model 1. The normal probability plot is almost a straight line. The histogram of residual and frequency plot for volume of cast 1 , density of cast and weight loss does not have normally distributed shape. The fitted values and residuals plot show the scatter distribution points in Figures 1(a), 1(b) and 1(c), since the scatter points made specific shape, this indicates that it is not a good model. Figure 1(d) shows the main effect plot of volume of cast, which shows that LC1, HC1 and WC1 have the highest significant effect on Volume of cast 1 . The $\mathrm{BC} 2, \mathrm{HC} 1$ and $\mathrm{WC} 1$ have the highest effect on density of cast 1 as shown in Figure 1(e). The Figure 1(f) shows that WC2 has the highest significant effect on weight Loss. 


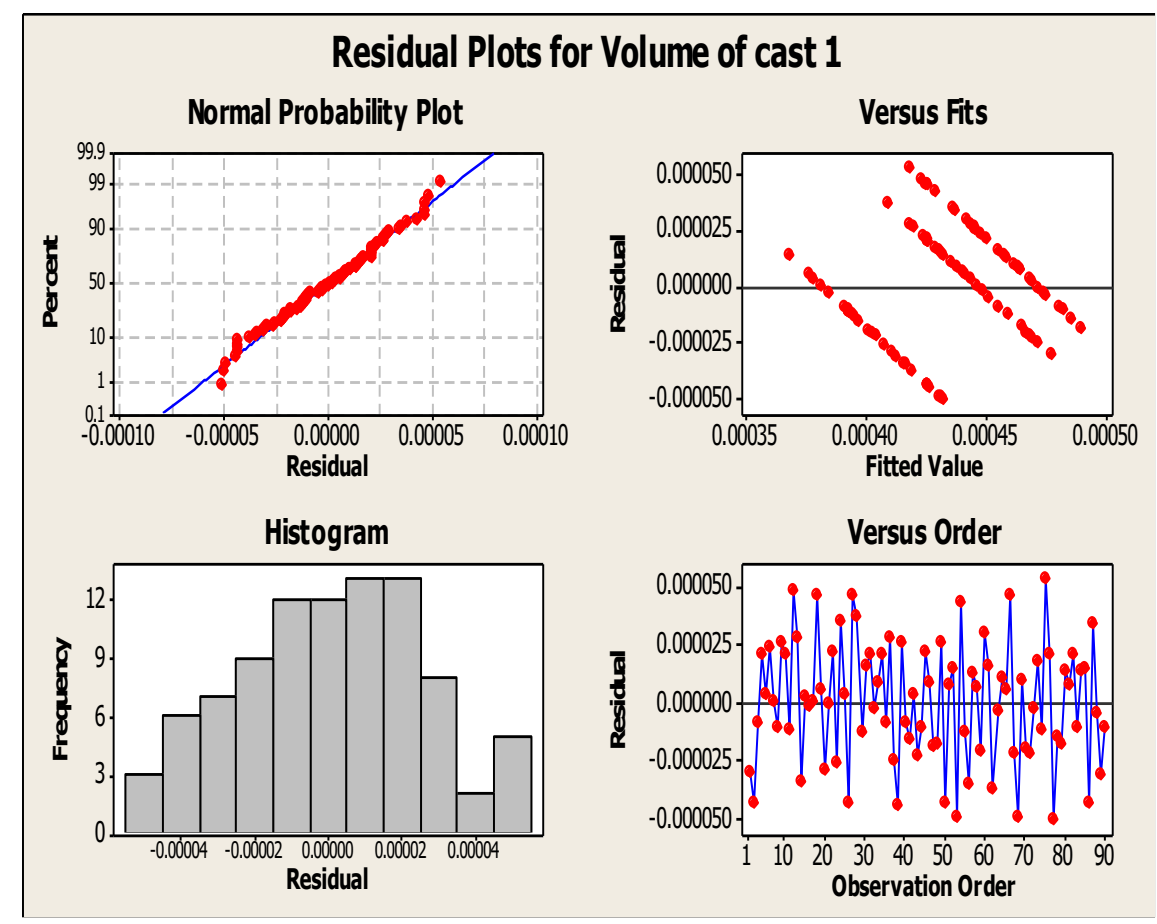

(a)

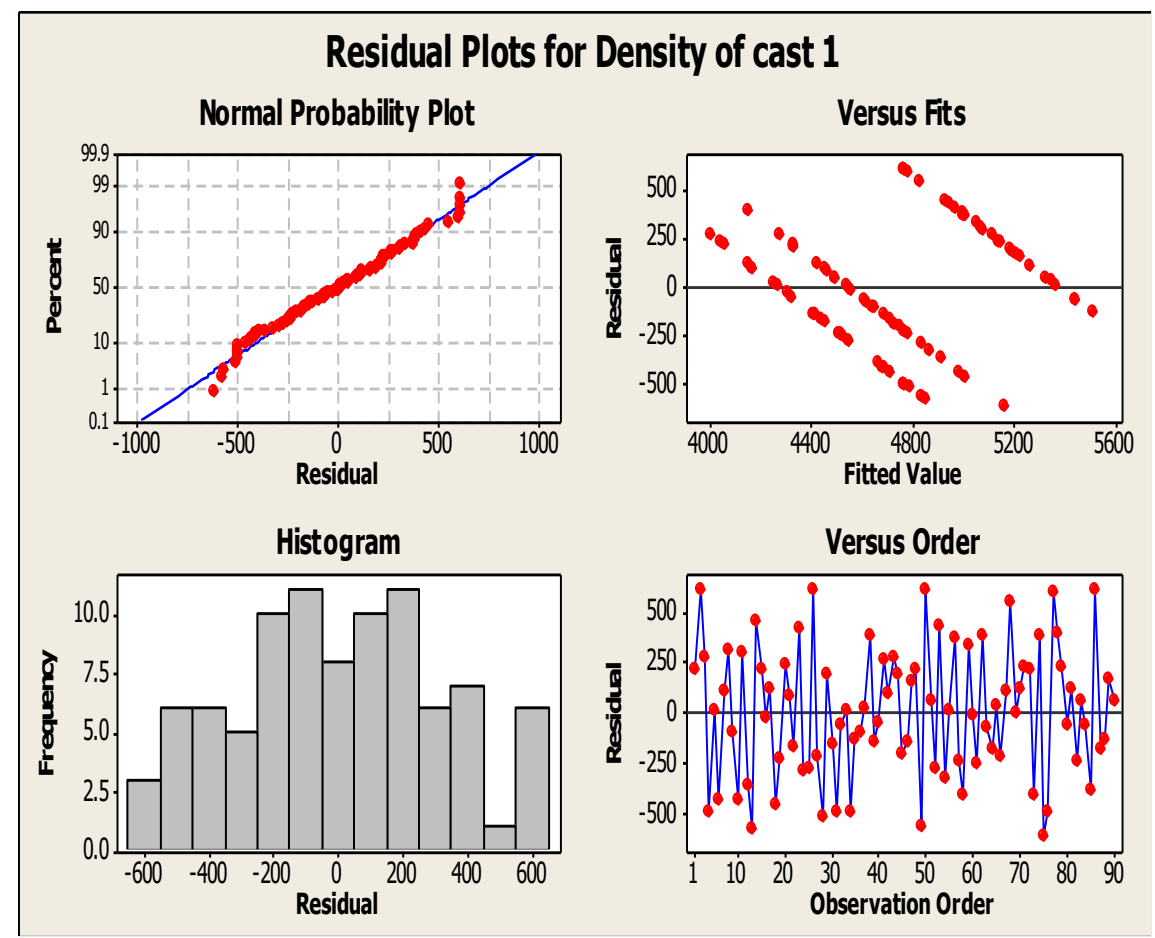

(b) 


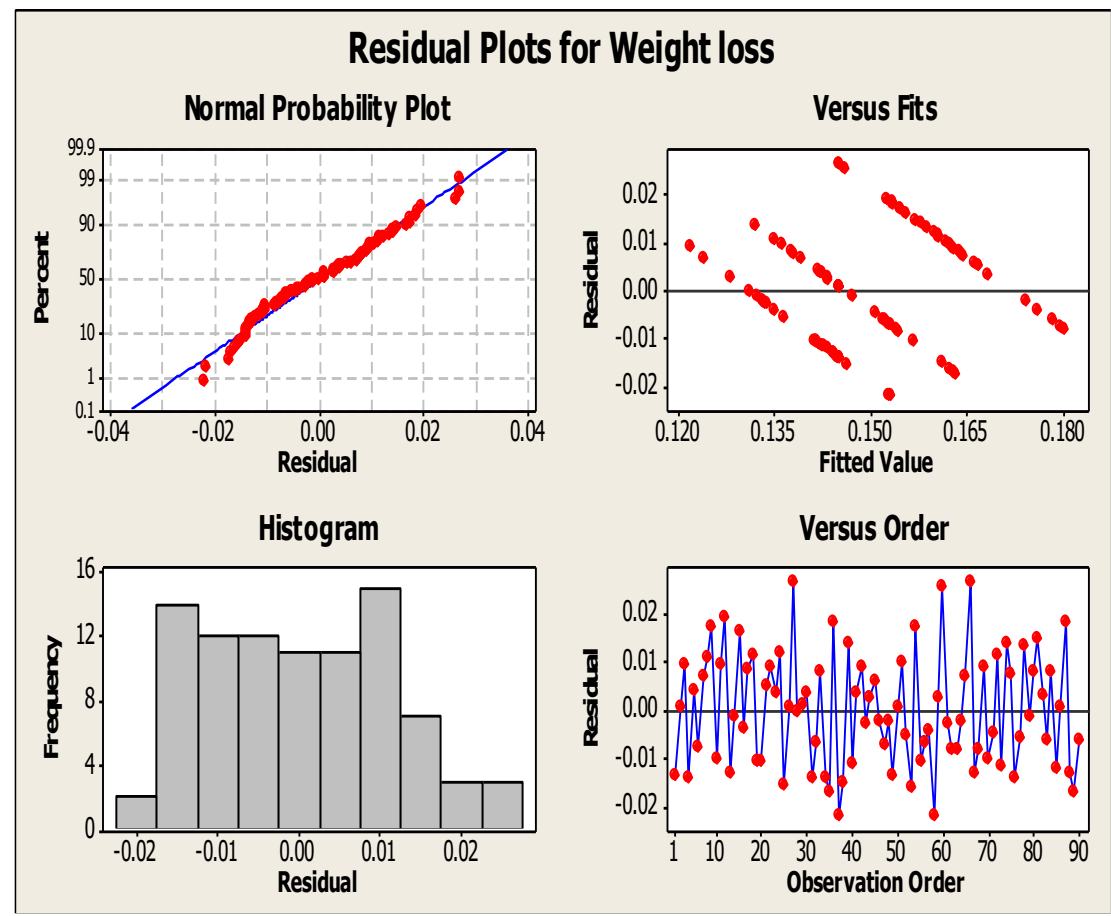

(c)

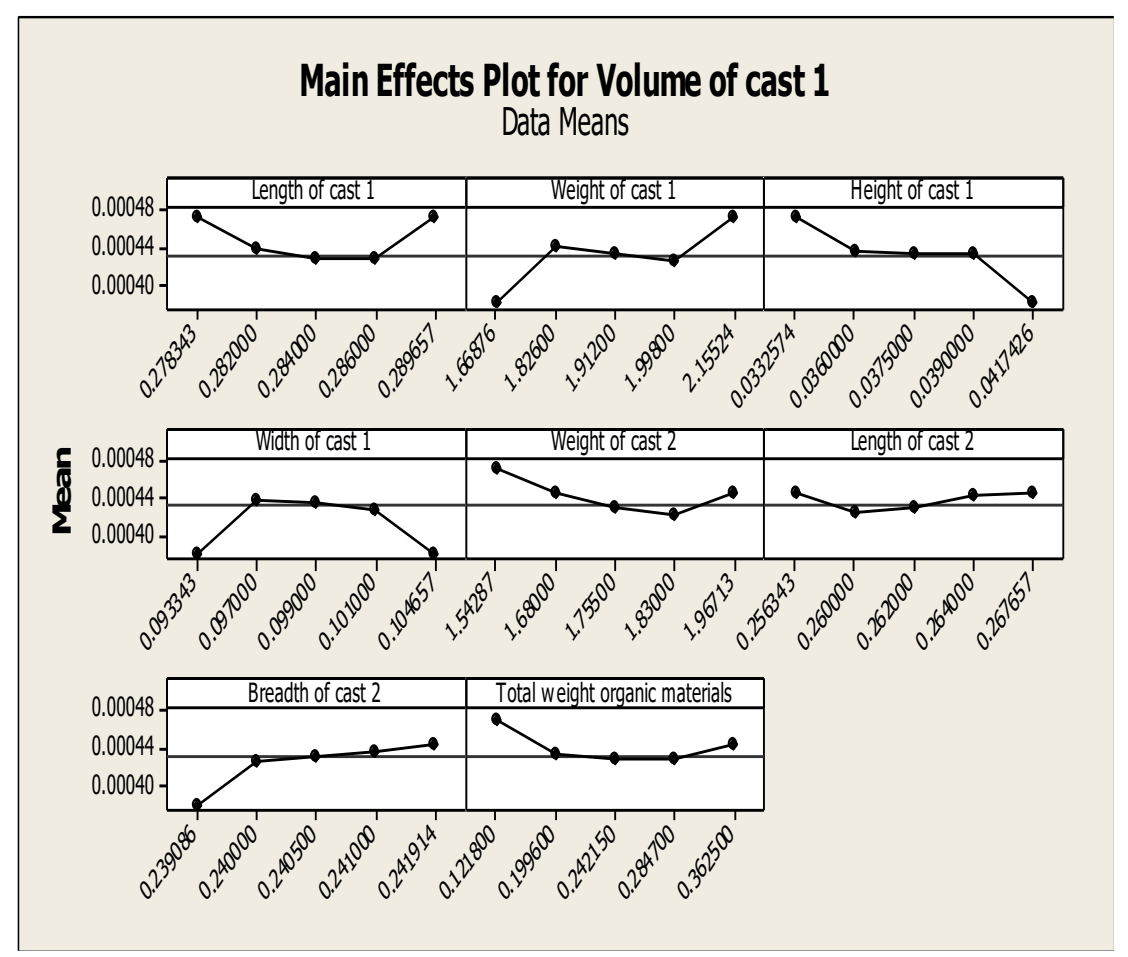

(d) 


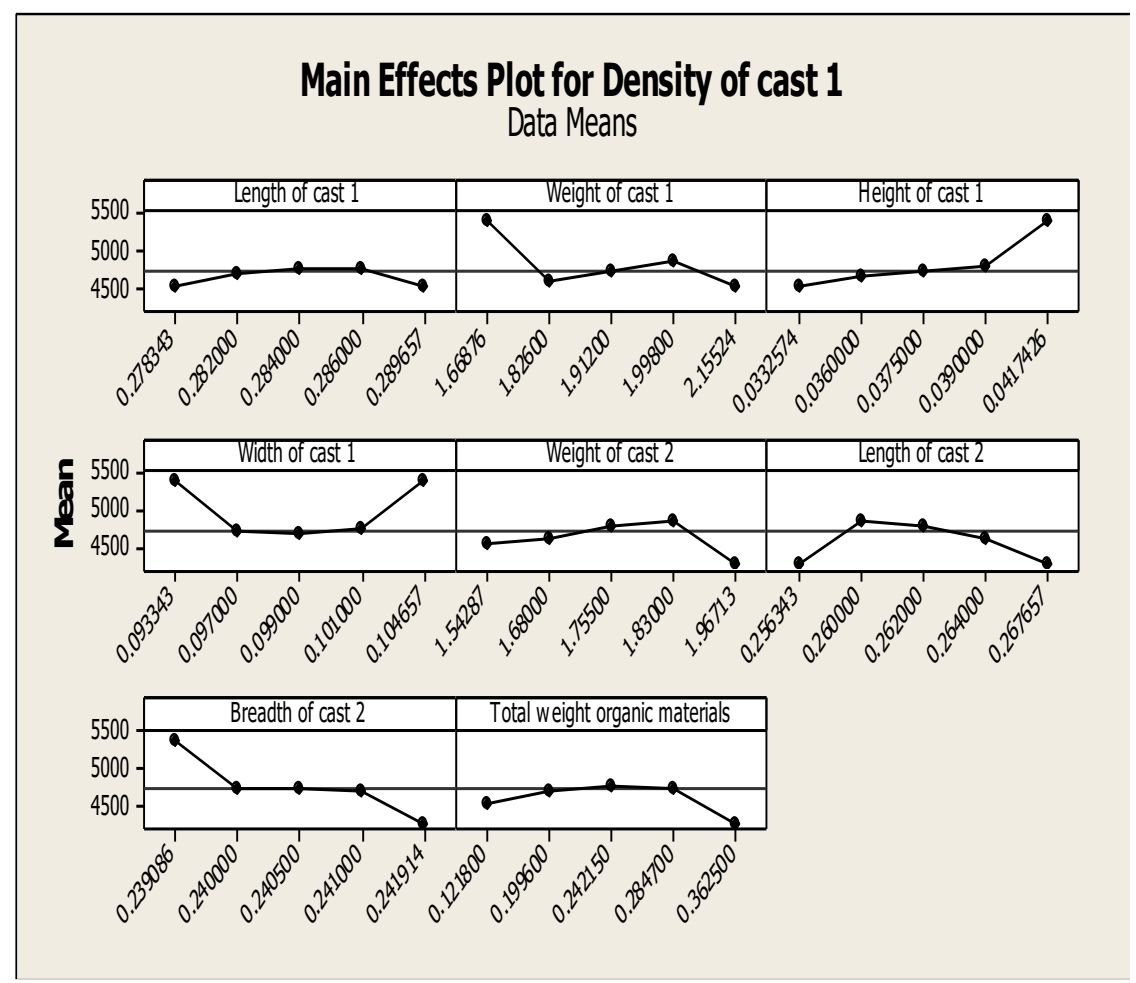

(e) 


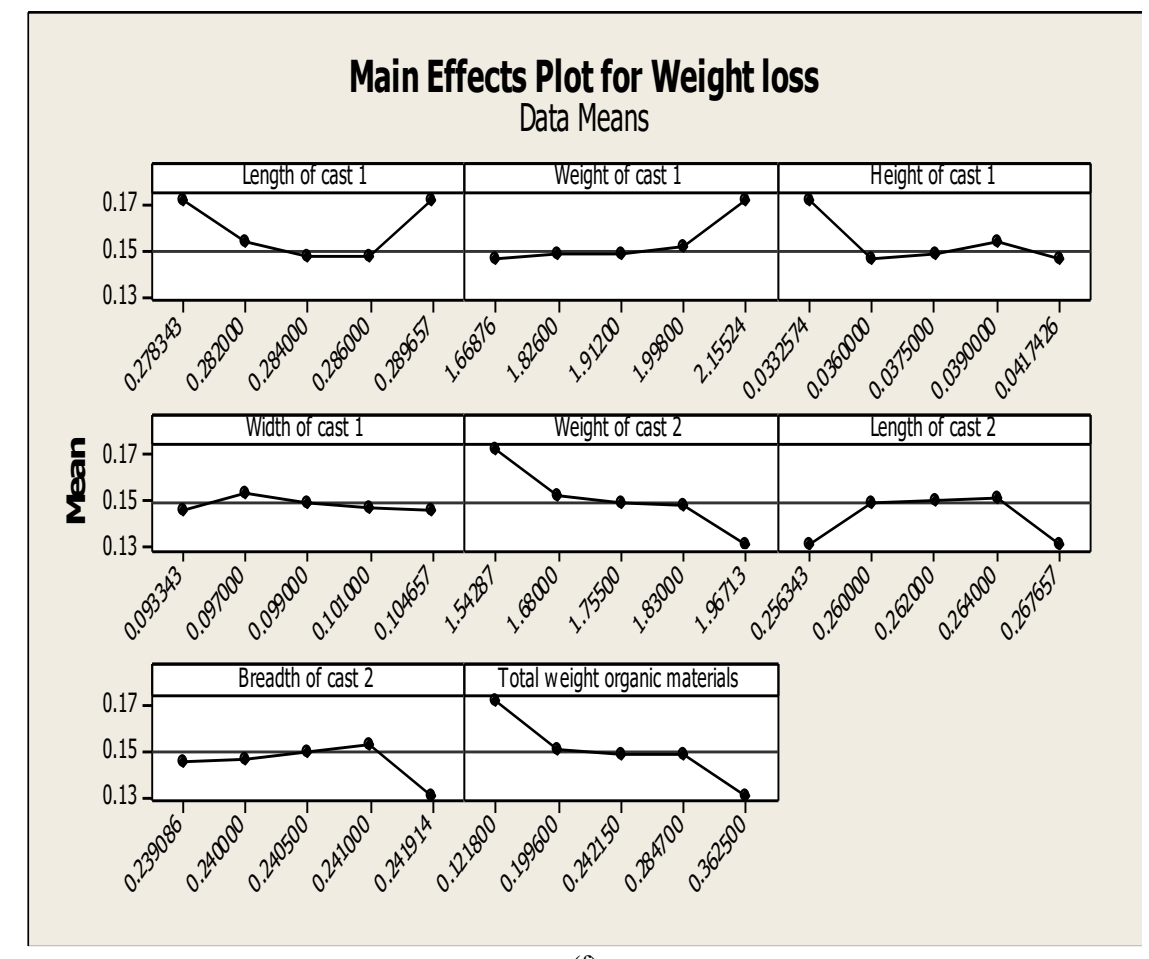

(f)

Figure 1(a), (b), (c), (d) and (e). Behavioural plots of variables

Figures 1(a) to 1(f) reveal the finding in terms of residual plots (Figures 1(a), 1(b) and 1(c) for volume of cast 1, density of cast 1 , and the weight loss, respectively). The Figures 1(d), 1(e) and 1(f) are the main effects plots for volume of cast 1 , density of cast 1 , and weight loss, respectively. A residual is the degree to which a point is when vertically measured from the regression line (error indicating the difference between predicted and observed values). Figures 1(a), 1(b) and 1(c) reveal how to imagine residuals of the casing process factors against the line of best fit. However, in interpreting residuals, it is often assumed that the errors (residuals) are self-sufficient and normally distributed. Figures 1(a), 1(b) and 1(c) all have good residual plots as they reveal high compacting points near the starting points and low concentration of points away from stating points. In addition, the plots are balanced about the starting points. However, the plots reveal that all the predictive information of casting process data are not totally portrayed, and this advances the reason for the existence of residuals. Recall that from Table 3, $R$-Squared is given as 54.63\%, 54.94\% and $53.29 \%$, respectively, for volume of cast 1 , density of cast 1 , and weight loss. As it stands, a higher value along the horizontal axis is related to a higher value along the vertical axis for all the three cases. However, at a particular value on the horizontal axis, the prediction of a value on the vertical axis of the density of cast 1 stands more accurate than that of volume of cast 1 while the prediction concerning volume of cast 1 will be more accurate the that of weight loss. Figures 1(d), 1(e) and 1(f) reveal the influence of one of the following variables (i.e. volume, length, density, height, width, breadth) on the dependent variables (such as weight loss), disregarding the influence of all other independent variables. It is common to have only one main effect attached to each independent variable. As revealed in Figure 1(d), the behaviour of graphs showing volume of cast 1 against length of cast 1 , length of cast 2, and total weight of organic materials is similar. In these cases, there is an initial decline, some constant values and growth 
characteristics. Furthermore, volume of cast 1, against weight of cast 1, and breadth of cast 2 are similar except that after the initial growth pattern of these options, for breadth of cast 2, there is a slower growth rate before a high increase. Figures $1(\mathrm{e})$ and $1(\mathrm{f})$ show different behaviours also.

\section{Conclusion}

The cast geometrical evaluation of A356 alloy composite reinforced with abori wood, pineapple sucker and Delonix regia tree droppings can have a substantial influence on casting efficiency in the melt shop. However, through a detailed literature review, no technical solution exists using the RSM to overcome the substantial melting hours lost due to product dimensional inaccuracies and the high cost of rework and scrap. This research gap prevails whereby melt shop workers rely on trial-and-error method for cast geometric optimisation of products. In this paper, the results of the surface response methodical application to the development of a wheel cover reveal the following. For the first case and the first response, volume of cast 1 , two terms were found to be statistically significant to the response. These are the interactions between weight of cast 1 and width of cast 1 (one term), and total weight of organic materials and length of cast 2 (second term). Research suggests that for the first case and the second response (density of cast 1), two terms also were statistically significant. The terms are the interactions between weight of cast 1 and width of cast 1 (one term), and height of cast 1 and breadth of cast 2 (second term). There is also evidence to suggest that three terms are statistically significant for the first case and the third response (weight loss). The terms are the square of length of cast 1 (first term), the interaction between weight of cast 1 and weight of cast 2 (second term) and total weight of organic materials and weight of cast 1 .

Hence, cast geometries of A356 alloy composite can impact positively on the melt shop casting process. Furthermore, the best safeguard against wastages through cast issues is to employ the developed RSM. The research community should take advantage of this work to eliminate waste due to inaccuracies. In this study, two main configurations were considered for analysis, namely the cuboid-shaped form and the canoe-shaped form. Future analysis could be directed at the following shapes: circular, elliptical, triangular, planar and concave. Furthermore, the RSM may be integrated into other models such as Taguchi methods and control charts for fruitful future research.

\section{References}

[1] Mao, F., Yan, G., Xuan, Z., Coa, Z. and Wang, T. (2015). Effect of Eu Addition on Microstructures and Mechanical Properties of A356 Aluminium Alloys, Journal of Alloys and Compounds, Vol. 650, 896-906.

[2] Ma, G., Li, R. and Li, R. (2016). Effects of Stress Concentration of Low Temperature Fracture Behaviour of A356 Alloy, Material Science and Engineering A, Vol. 667, 459-467.

[3] Nwobi-Okoye, C.C., Ochieze, B. Q. and Okiy S. (2019). Multi-Objective Optimisation And Modeling of Age Hardening Process Using ANN, ANFIS and Genetic Algorithm: Result from Aluminium Alloy A356/Cow Horn Particulate Composite, Journal of Materials Research and Technology, Vol. 8, No. 3, 3054-3075.

[4] Chen, Z-W., Ma, C-Y. and Chen, P. (2012). Eutectic Modification of A356 Alloy with Li Addition Through DSC and Miedema Model, Transactions of Nonferrous Metals Society of China, Vol. 22, 42-46.

[5] Nampoothiri, S., Balasundar, I., Raj, B., Murty, B.S. and Ravi, K.R. (2018). Porosity Alleviation and Mechanical Property Improve of Strontium Modified A356 Alloy by Ultrasonic Treatment, Material Science Engineering A, Vol. 724, 586-593.

e-ISSN: 2289-7771

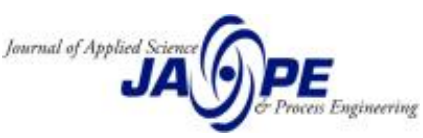


[6] Ibragimova, E., Vermeeren, A., Vink, P., Mueller, N. and Verboom L. (2015). The Smart Steering Wheel Cover Design: A Case Study of Industrial-Academic Collaboration in Human-Computer Interaction, In: Nah F.F-H and Tan C-H (Eds): $2^{\text {nd }}$ International Publishing Switzerland, DOI:1007/978-3-319-20895-4-2.

[7] Pandya, A., Thakkar, S., Bhatt, A.V. and Anakia, A. (2015). Research Paper on Design Modification and Analysis of Automobile Wheel Run Using Finite Element Analysis, International Journal for Scientific Research and Development, Vol.3, No.3, 3027-3030.

[8] Lou, Y.F. (2016). Key Points of Control of Automobile Covering Parts, Forging and Metal Forming, Vol.4, 5456.

[9] Haibo, Z. and Bin, D. (2019). Research on Forming Technology of Automobile Rear Wheel Cover Panels, IOP Conference Series:

[10] Jadhav, P.R., Sridhar, B.R., Nagaral, M..and Harti, J.I. (2017). Evaluation of Mechanical Properties of $B_{4} C$ a Graphite Particulates Reinforced A356 Alloy Hybrid Composites, Materials Today, Proceeding, Vol. 4, 9972 9976.

[11] Sheikh-Jaben, F., Cockcroft, S.L., Maijer, D.M. and Phillion, A.B. (2019). Comparison of the Semi-Solid Constitutive Behaviour of A356 and B206 Aluminium Foundry Alloys, Journal of Material Processing Technology, Vol. 266, 37-45.

[12] Mortsell, E.A., Quan Marioara, C.D. and Li, Y. (2019). Precipitation in an A356 Foundry Alloy with Cu Additions - A Transmission Electron Microscopy Study, Journal of Alloys and Compounds, Vol. 785, 11061114.

[13] Aguirre-De La Torre, E., Perez-Bustamante, R., Camarillo-Cisneros, J., Gomez-Esparza, C.D., Medrano-Prieto, H.M. and Martinez-Sanchez, R. (2013). Mechanical Properties of the A356 Aluminium Alloy Modified with $\mathrm{La} / \mathrm{Ce}$, Journal of Rare Earths, Vol.31, No.8, 811-816.

[14] Tsai, Y-C., Chou, C.-Y., Lee, S.-L,, Lin, C.-K., Lin, J.-C. and Lim, S.-W. (2009). Effect of Trace La Addition on the Microstructures and Mechanical Properties of A356 (Al-7Si-0.35Mg) Aluminium Alloys, Journal of Alloys and Compounds, Vol. 487, No.1-2, 157-162.

[15] Palanikumar, K. and Karthikeyan, R. (2006). Optimal Machining Conditions for Turning of Particulate Metal Matrix Composites Using Taguchi and Response Surface Methodologies, Machining Science and Technology: An International Journal, Vol. 10, No.4, 417-433.

[16] Palanikumar, K., Muthukrishnan, N. and Hariprasad K.S. (2008). Surface Roughness Parameters Optimisation in Machining A356/Sic/20p Metal Matrix Composites by PCD Tool Using Response Surface Methodology and Desirability Function, Machining Science and Technology: An International Journal, Vol. 12, No. 4, 529-545.

[17] Balasubramanian, K., Nataraj, M. and Duraisany, P. (2019). Machinability Analysis and Application of Responsesurface Approach on CNC Turning of LM6/SiCp Composites, Materials and Manufacturing Processes, Vol. 34, No.12, 1389-1400.

[18] Bawono, B., Anggoro, P.W., Bayuseno, A.P., Jamari, J. and Tauviquirrahman, M. (2019). Milling Strategy Optimised for Orthotics Insole to Enhance Surface Roughness and Machining Time by Taguchi and Response Surface Methodology, Journal of Industrial and Production Engineering, Vol.36, No.4, 237-257.

[19] Radhika, N. and Raghu, R. (2018). Study on Three-Body Abrasive Wear Behaviour of Functionally Graded $\mathrm{Al} / \mathrm{TiB}_{2}$ Composite Using Response Surface Methodology, Particulate Science and Technology: An International Journal, Vol.36, No.7, 816-823.

[20] Patel, M., Krishna, G.C.P. and Parappagoudar, B. (2015). Modeling of Squeeze Casting Process Using Design of Experiments and Response Surface Methodology, International Journal of Cast Metals Research, Vol.28, No.3, 167-180.

e-ISSN: 2289-7771

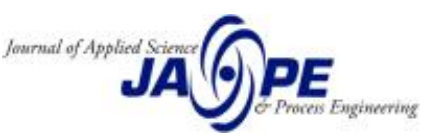


[21] Mohal, S. and Kumar ,H. (2016). Parametric Optimisation of Multi-Walled Carbon Nanotube-Assisted Electric Discharge Machining of Al-10\% SiCp Metal Composite by Response Surface Methodology, Materials and Manufacturing Processes, Vol.32, No.3, 263-273.

[22] Adalarasan, R., Santhanakumar, M. and Shanmugasundaram A. (2017). Investigation in Solid-State Joining of $\mathrm{Al} / \mathrm{SiC} / \mathrm{Al}_{2} \mathrm{O}_{3}$ Composite Using Grey-Based desirability (GBD) and Response Surface Plots, Journal of Chinese Institute of Engineers, Vol. 40, No.1, 55-65.

[23] Alvarez, M.J., Iizarbe, I., Viles, E. and Tanco, M. (2009). The Use of Genetic Algorithms in Response Surface Methodology, Quality Technology and Quantitative Management, Vol. 6, No.3, 295-307.

[24] Mishra, S.K., Fioy, H. and Dutta, K. (2018). Influence of Ratcheting Strain and Tensile Properties of A356 Alloy, Materials Today Proceedings, Vol. 5, 12403-12408.

[25] Zhang, X., Hang, L.K., Zhang B., Chen, Y.Z., Duan, S.Y., Liu, G., Yang, C.L. and Liu, F. (2019). Enhanced Strength and Ductility of A356 Alloy Due to Composite Effect of Near-Rapid Solidification and ThermoMechanical Treatment, Materials Science and Engineering A, Vol. 753, 168-178.

[26] Liu, Z., Wang, X., Han, Q. and Li, J. (2014). Effects of the Addition of Ti Powder on the Microstructure and Mechanical Properties of A356 Alloy, Powder Technology, Vol. 253, 751-756.

[27] Lin, J., Zhao, H. and Huang, J. (2019). Spatial Interfacial Heat Transfer and Surface Characteristics During Gravity Casting of A356 Alloy, Transaction of Non ferrous Metals Society of China, Vol. 29, 43-50.

[28] Pramod, S.L., Ravikirana, Rao A.K.P., Murty, B.S. and Bakshi, S.R. (2016). Effect of Sc Addition and T6 Aging Treatment on the Microstructure Modification and Mechanical Properties of A356 Alloy, Material Science \& Engineering A, Vol. 674, 438-450.

[29] Das, P., Bhurya, B., Samanta, S.K. and Duta, P. (2019). Studies on Die Filling of A356 Al Alloy and Development of a Steering Knuckle Component Using Rheo Pressure Die Casting System, Journal of Materials Processing Technology, Vol. 271, 293 - 311.

[30] Nie, F., Dong, H., Chen, S., Li, P., Wang L., Zhao Z., Li X. and Zhang H. (2018). Microstructure and Mechanical Properties of Pulse MIG/Welded 6061/A356 Aluminium Alloy Dissimilar Built Joints, Journal of Materials Science and Technology, Vol 34, 551-560.

[31] Nwafor, S., Oke, S. and Ayanladun, C. (2019). Taguchi Optimisation of Cast Geometries for A356/Organic Particulate Aluminium Alloy Composites Using a Two-Phase Casting Process, Journal of Applied Science \& Process Engineering, Vol. 6, No. 2, 386-411.

[32] Pai, D., Rao, S., Shetty, R. and Nayak, R. (2010). Application of Response Surface Methodology on Surface Roughness in Grinding of Aerospace materials (6061A1-15Vol\% $\mathrm{SiC}_{25 \mathrm{p}}$ ), ARPN Journal of Engineering and Applied Sciences, Vol. 5, No. 6, 23-28.

[33] Mwaniki, W.A., Joseph, K., John, M., Wellington, M., Catherine, K. and Bramuel E. (2017). Application of Response Surface Methodology for Determining Optimal Factors in Maximisation of Maize Grain Yield and Total Microbial Count in Long Term Agricultural Experiment, Kenya, Science Journal of Applied Mathematics and Statistics, Vol. 5, No. 6, 200-209.

e-ISSN: 2289-7771

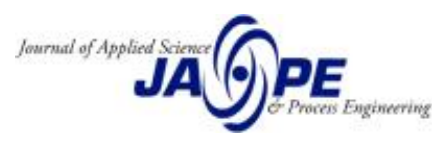

